\title{
Solid State Joining of High Temperature Alloy Tubes for USC and Heat-Exchanger Systems
}

\author{
Final Technical Report \\ January $1^{\text {st }} 2007$-December $31^{\text {st }} 2011$
}

Principal Investigator:

Bimal K. Kad

Department of Structural Engineering

University of California-San Diego, La Jolla, CA 92093-0085

Tel: (858) 534 7059; Fax: (858) 534-6373; e-mail: bkad@ucsd.edu

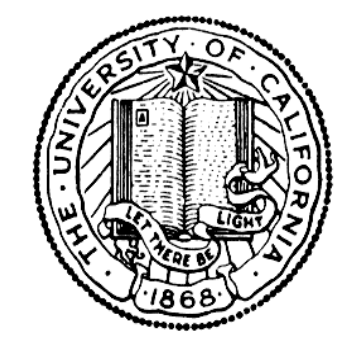

Issue Date: August $15^{\text {th }} 2012$

\begin{abstract}
National Energy Technology Laboratory
Contract Award: DE-FG26-07NT43073
\end{abstract}

For

Development of Technologies and Capabilities for Developing Coal, Oil and Gas Energy Resources 
This report was prepared as an account of work sponsored by an agency of the United States Government. Neither the United States Government nor any agency thereof, nor any of their employees, makes any warranty, expressed or implied, or assumes any legal liability or responsibility for the accuracy, completeness, or usefulness of any information, apparatus, product, or process disclosed, or represents that its use would not infringe privately owned rights. Reference herein to any specific commercial product, process, or service by trade name, trademark, manufacturer, or otherwise, does not necessarily constitute or imply its endorsement, recommendation, or favoring by the United States Government or any agency thereof. The views and opinions of authors expressed herein do not necessarily state or reflect those of the United States Government or any agency thereof. 


\title{
Solid State Joining of High Temperature Alloy Tubes For USC and Heat-Exchanger Systems
}

\author{
Table of Contents
}

Executive Summary 1

1. Background \& Problem Statement 2

1.1 Material Issues in Rankine Cycle Programs 2

1.2 Material Issues in HIPPS and IGCC Programs 2

1.3 Welding Problem and Developmental Challenges 3

2. Experimental Task Structure 3

Task1 Non Fusion Joining of ODS-MA956 3

Task 2 Joint Microstructure and Integrity Evaluation 3

Task 3 Joint Creep Performance Evaluation 4

3. Experimental Program Activity 4

Task 1 Program Activity \& Results 4

Task 2 Program Activity \& Results 6

Task 3 Program Activity \& Results $\quad 12$

3.1 Creep Testing - Similar Materials Joints 13

3.2 Creep Testing - Dissimilar Material Joints 17

4. Results and Discussion 19

5. References 21 


\section{List of Tables}

1. Test matrix of MA956-MA956 tube butt joints produced via inertia welding 4

2. Recrystallization of MA956-MA956 tube butt joints produced via inertia welding 8

3. Candidate material properties for MA956-Nickel base alloy dissimilar joints 10

4. Creep test performance for MA956-MA956 similar joints 17

5. Creep test performance for MA956-IN601 dissimilar joints 19 


\section{List of Figures}

1. Material selection grid for the USC Rankine Cycle program indicating the gradual migration from ferritic to austenitic steels to the advanced Ni-base alloys for higher temperature performance.

2. DOE material metric for HIPPS and IGCC concept heat exchangers for service at $1000^{\circ} \mathrm{C}$ and above. ODS materials are suitable metallic material for this service.

3. Sequences in the inertia welding of MA956 tube a) spin up of tube, b) initial contact under applied pressure, c) flywheel stopped at a prescribed rpm drop, d) cool down and, e) the as-welded tube section.

4. Typical MA956-MA956 butt welds produced under different welding conditions.

5. IN740-IN740 rod joints produced with material upsets in the $0.125 "-0.360 "$ range.

6. IN740-MA956 rod joints produced with material upsets in the $0.125 "-0.410$ " range.

7. Optical Micrographs of MA856 butt-joints in the as-welded (left) and recrystallized (right) condition. Figure 7.2 and 7.1 (Top) are respectively the as-welded and post-weld heat treated microstructure across the Joint\# 1 where only primary recrystallization is observed. In contrast, Figure 7.4 and 7.3 (Bottom) are the as-welded and post-weld heat treated microstructure of Joint \# 3 where ample secondary grain growth is observed in the weld region. This latter microstructure yields enhanced hoop creep performance.

8. MA956-IN601 dissimilar alloy butt joint.

9. Metallography of dissimilar alloy IN601 and MA956 inertia welded joint in the as polished (a) and etched (b) condition. The interface is clean with a slight intermixed layer seen in the as-polished cross-section.

10. Micorhardness profile a) across the IN601-MA956 dissimilar joint at different HT. b) Backscatter SEM image of the interface (HT: 1300C-1hr) with an hardness indent in the vicinity.

11. Compositional profile of Al, Cr, Fe, Ni species across the IN601 (left)-MA956 (right) inertia welded interface. a) As-welded section, b) Heat-Treated at $1300^{\circ} \mathrm{C}-1 \mathrm{hr}$. Selected energy dispersive compositional scans for c) Nickel and d) Aluminum across the heat treated joint interface.

12. Room temperature three point bend tests in as-welded a) MA956-MA956, b)

IN740-IN740 similar and c) IN740 - MA956 dissimilar joints.

13. a) Creep samples spark machined from the inertia butt weld joints, b) Creep behavior 
14. Incremental temperature creep test of similar alloy Joint 1 (Table 1). The fine grain recrystallized structure of the joint region results in poor creep response.

15. Incremental temperature creep test of similar alloy joint 3 (Table 1). The coarse grained recrystallized structure of the joint region results in good creep response.

16. Scanning electron micrographs of creep test failures in Joint 1 failed at $850^{\circ} \mathrm{C}$ (left) and 2) Joint 3 failed at $950^{\circ} \mathrm{C}$ temperature (right). Both tests performed at $2 \mathrm{Ksi}$ and the improved performance of Joint 3 versus Joint 1 is attributed directly to the coarse grained recrystallized microstructure (see Figure 4.3). Such micrographs provide ready assessment of the efficacy of joining parameters employed and the subsequent recrystallization microstructure that may improve joint creep performance as evaluated here.

17. Scanning electron micrographs of creep failure in Joint 3 tested at $900^{\circ} \mathrm{C}$ (left). Close up detail (right) indicating the random distributions of small grained regions (with small diameter lobes) in the test cross-section.

18. Incremental temperature creep test of dissimilar alloy joint recrystallized at $1300^{\circ} \mathrm{C}$. The joint performance is substantially inferior to the MA956-MA956 joint.

19. Scanning electron micrograph of creep test failure substructure in dissimilar joint failed at $850^{\circ} \mathrm{C}$.

20: Differences in creep response for the as-welded and heat treated MA956-IN601 joints. As-welded samples show a brief but distinct tertiary regime and fail at high levels of strain. Plots are arbitrarily displaced for clarity.

21. Observed creep life at temperature for three different processed inertia welded joints all tested at 2Ksi stress. Current results (top curve, brown) are compared to earlier results [8]. 


\section{Executive Summary}

The principal objective of this project was to develop materials enabling joining technologies for use in forward looking heat-exchanger fabrication in Brayton cycle HIPPS, IGCC, FutureGen concepts capable of operating at temperatures in excess of $1000^{\circ} \mathrm{C}$ as well as conventional technology upgrades via Ultra Super-Critical (USC) Rankine-cycle boilers capable of operating at $760^{\circ} \mathrm{C}(1400 \mathrm{~F}) / 38.5 \mathrm{MPa}(5500 \mathrm{psi})$ steam, while still using coal as the principal fossil fuel. The underlying mission in Rankine, Brayton or Brayton-Rankine, or IGCC combined cycle heat engine is a steady quest to improving operating efficiency while mitigating global environmental concerns. There has been a progressive move to higher overall cycle efficiencies, and in the case of fossil fuels this has accelerated recently in part because of concerns about greenhouse gas emissions, notably $\mathrm{CO}_{2}$. For a heat engine, the overall efficiency is closely related to the difference between the highest temperature in the cycle and the lowest temperature. In most cases, efficiency gains are prompted by an increase in the high temperature, and this in turn has led to increasing demands on the materials of construction used in the high temperature end of the systems. Our migration to new advanced Ni-base and Oxide Dispersion Strengthened (ODS) alloys poses significant fabrication challenges, as these materials are not readily weldable $[1,2]$ or the weld performs poorly in the high temperature creep regime. Thus the joining challenge is two-fold to a) devise appropriate joining methodologies for similar/dissimilar Ni-base and ODS alloys while b) preserving the near baseline creep performance in the welded region. Our program focus is on solid state joining of similar and dissimilar metals/alloys for heat exchanger components currently under consideration for the USC, HIPPS and IGCC power systems. The emphasis is to manipulate the joining methods and variables available to optimize joint creep performance compared to the base material creep performance.

Similar and dissimilar butt joints were fabricated of MA956, IN740 alloys and using inertia welding techniques. We evaluated joining process details and heat treatments and its overall effect on creep response. Fixed and incrementally accelerated temperature creep tests were performed for similar and dissimilar joints and such incremental creep life data is compiled and reported. Long term MA956-MA556 joint tests indicate a firm 2Ksi creep stress threshold performance at $850^{\circ} \mathrm{C}$ with a maximum exposure of over 9725 hours recorded in the current program. A Larsen Miller Parameter (LMP) of 48.50 for a $2 \mathrm{Ksi}$ test at $850^{\circ} \mathrm{C}$ was further corroborated with tests at $2 \mathrm{Ksi}$ stress at $900^{\circ} \mathrm{C}$ yielding a $\mathrm{LMP}=48.80$. Despite this threshold the joints exhibit immense temperature sensitivity and fail promptly when test temperature raised above $900^{\circ} \mathrm{C}$. In comparison the performance of dissimilar joints was inferior, perhaps dictated by the creep characteristics of the mating nickel-base alloys. We describe a parametric window of joint development, and post weld heat treatment (PWHT) in dissimilar joints with solid solution (IN601, IN617) and precipitate strengthened (IN740) materials. Some concerns are evident regarding the diffusion of aluminum in dissimilar joints during high temperature recrystallization treatments. It is noted that aggressive treatments rapidly deplete the corrosion protecting aluminum reservoir in the vicinity of the joint interface. Subsequently, the impact of varying PWHT has been evaluated in the context on ensuing creep performance. 


\section{Background \& Problem Statement}

\subsection{Material Issues in USC Rankine Cycle Programs}

Current boiler materials, typically operating below $600^{\circ} \mathrm{C}$, Figure 1, are replacement candidates with advanced materials like ferritics (SAVE12), austenitics (Super 304H, HR6W), and Superalloys (Haynes ${ }^{\circledR} \quad 230, \quad$ CCA617, INCONEL ${ }^{\circledR}$ 740) [1,2] for higher system performance. Current stateof-the art boilers use advanced ferritic steels in the boiler and headers and austenitic steels in the superheater. Austenitic steels have superior high temperature strength but their use in boilers is limited to

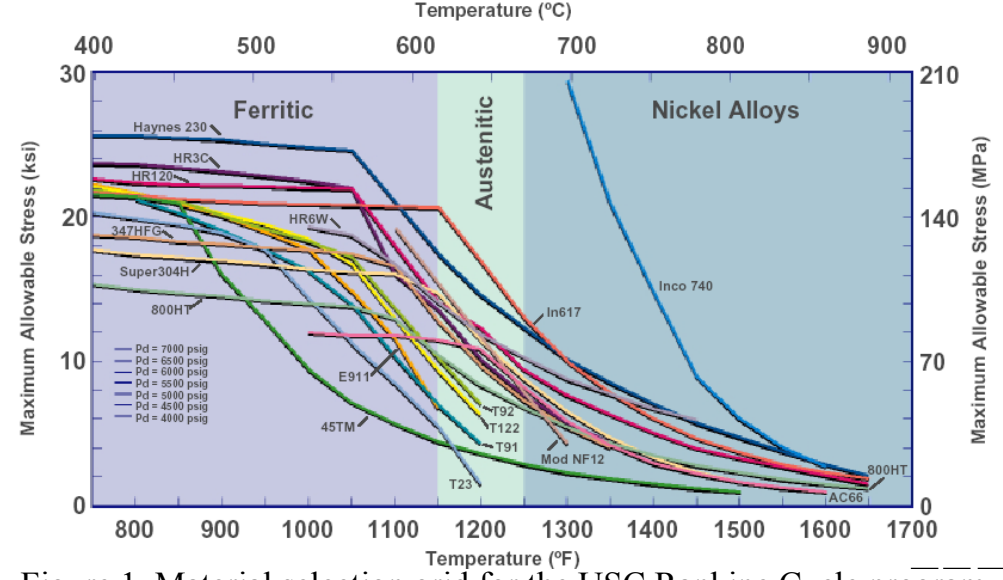

Figure 1. Material selection grid for the USC Rankine Cycle program indicating the gradual migration from ferritic to austenitic steels to the advanced Ni-base alloys for higher temperature performance. [2] tubing due to cracking in thick sections during cyclic operation. Neither ferritic nor austenitic steels are expected to meet the target temperatures for the hottest sections of a USC boiler operating at $760^{\circ} \mathrm{C}(1400 \mathrm{~F}) / 38.5 \mathrm{MPa}(5500 \mathrm{psi})$ steam. Thus, nickel-based super alloys must provide the next step for increasing steam temperatures. Future power systems will undergo inevitable material transitions from ferritic to austenitic steels to the new nickel base alloys.

\subsection{Material Issues in HIPPS and IGCC Programs}

Current HIPPS program designs involving indirectly-fired gas turbine cycles are aimed at high cycle efficiencies, of the order of $47 \%$ based on the higher heating values (HHV) of the fuel, and involve open cycle systems in which air is heated to $760^{\circ} \mathrm{C}$ in a metallic heat exchanger, followed by further heating to $982^{\circ} \mathrm{C}$ in a natural gas-fired ceramic heat exchanger $[3,4]$. Successful implementation of either directly or indirectly fired cycle technologies will require the development of a durable coal-fired heat exchanger capable of heating the working fluid to very high temperatures, in addition to adapting a gas turbine for this particular duty. The DOE material metric, Figure 2, suggests that prime candidate material for a high temperature heat exchanger for HIPPS and IGCC concepts are oxide dispersion strengthened (ODS) alloys. In practice the form of the heat exchanger surfaces may be considerably different from those in a steam boiler. Nevertheless, the fireside corrosion problems will be similar to those in current coal-fired

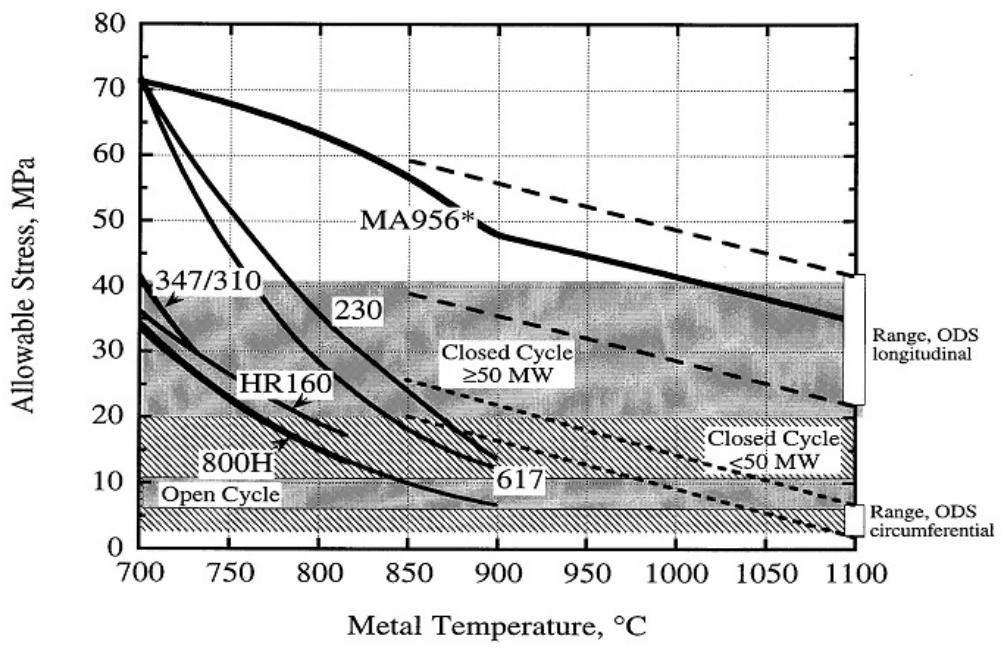

Figure 2. DOE material metric for HIPPS and IGCC concept heat exchangers for service at $1000^{\circ} \mathrm{C}$ and above. Note that ODS materials are suitable metallic material for this service. 
boilers, with some fuels being less aggressive than others, but with much higher tube metal temperatures. On the working fluid side, the heat exchanger wastage mechanism will be the same as gas turbine materials problems, or less severe, than in a conventionally fired turbine using a clean fuel.

\subsection{The Welding Problem and Developmental Challenges}

Steam Program Materials: Conventional arc welding practices in the boiler industry include submerged arc welding (SAW) and its many variants as SMAW, GTAW etc. Arc welding has performed admirably in its application to ferritic, austenitic steels and therefore the process of first choice in proposed USC program upgrades. However, materials evolution from conventional ferritic, austenitic to the novel nickel-base alloys presents its attendant fabrication and joining challenges that are at odds with the prevailing industrial practices and preferences. For example, the SAW a high deposition rate process favored by boilermakers for thick sections might not be feasible for Ni-base materials. Current USC program trials on Inconel 740 in similar/dissimilar welds have been unsuccessful [2], and the process is being abandoned, at least on these alloys. Inconel 740 has also been found susceptible to liquation cracking problem unique to the fusion based welding processes $[2,5]$ and consistent with prior literature $[6,7]$ on superalloys. Significant effort must therefore be expended in modifying existing practices to accommodate these new generation Ni-base alloys in the boiler community. In particular, joining methodologies must be code qualified and an entire database of weldment performance must be assembled. We can only surmise that such developmental challenges will be further exacerbated in the case of transition dissimilar metal joints where little or no prior knowledge database exists.

HIPPS, IGCC Candidate Materials: The outlook for ODS materials is straightforward as they cannot be subjected to a fusion based joining process. The density disparity between the matrix and the dispersoid precludes any melt based joining, as the dispersion will simply float away. Solid-state welding procedures like a) Inertia welding, b) Flash welding and c) Magnetic Pulse welding and d) Braze/Diffusion welding are the norm in this developmental regime. Figure 3 shows various butt and lap joints attempted on ODS-MA956 alloys under current programs. These efforts are in their infancy and will require significant expenditures of research effort and capital to develop the essential property database generation and evaluation.

\section{§ 2. Experimental Task Structure}

The experimental work reported here is described in the context of the task structure outlined below. For the revised duration of this program through December $31^{\text {st }} 2011$ and required quarterly reporting we will refer to this task structure for clarity and precise reference.

Task 1: Non Fusion Joining of ODS-MA956 and IN740 alloys

$$
\begin{aligned}
& \text { 1.1 MA956 - MA956 - Inertia Welding; Similar Tube butt joint fabrication } \\
& \text { 1.2 IN740 - IN740 - Inertia Welding; Similar butt joint fabrication } \\
& \text { 1.3 MA956 - IN740 - Inertia Welding; Dissimilar butt weld fabrication }
\end{aligned}
$$

Task 2: Joint Microstructure and Integrity Evaluation: 


\subsection{Post Weld heat treatment for grain structure: static and gradient}

\subsection{Microstructure characterization, Joint integrity \& HAZ evaluation}

\subsection{High Temperature testing and stress-rupture response}

Task 3: Joint Creep Performance Evaluation:

\subsection{Transverse creep and stress-rupture response: accelerated step tests}

3.2 Transverse creep and stress-rupture response: long term creep-life tests

\subsection{Deformation and Failure microstructure characterization}

\section{§3. Experimental Program Activity}

Task 1 Results: The materials for inertia welding were obtained from material vendors and from existing research programs. The ODS-MA956 was made available in $1 / 4$ "wall, $2 \frac{1}{2}$ " OD tube in the unrecrystallized state from our current and prior collaborations with Special Metals Corp. Candidate material for Nickel-base alloys were reevaluated - given the difficulty of acquiring the material in required tube size to be mated to the existing ODS alloy tubes. At the outset IN601 was available in a similar tube form and became the model material to study the intricacies of dissimilar joints between ODS and nickel-base materials. The nickel base alloy materials of choice were IN740, Haynes 230 and CCA617. Each of these alloys is also under consideration in the Ultra-critical Steam Cycle programs. Such nickel base alloys were readily available in rod form and were an attractive option to perform rod - rod butt joints of similar and dissimilar configurations. Consequently IN740 rods of 5/8" diameter were also procured from Special Metals for similar and dissimilar joints. Additionally $2 \frac{1}{2}$ " OD Haynes 230 rod stock was made available via an existing USC program effort. This large diameter Haynes 230 rod was intended for MA956 Tube to Haynes 230 Rod stock butt joints in a manner similar to end-cap butt joints.

An average of 5-6" long sections were machined for inertia welding trails, taking care to ensure that the end faces are perfectly normal to the long axis of the tube. This end face preparation ensures that the mating surfaces are orthogonal to the rotational axis for maximum interfacial contact for frictional heating and joining. All joints were fabricated using the Caterpillar model 150B, 180B single stage inertia welding machines. Initial trials were attempted on model 150B followed by a production style configuration adopted for the 180B model which provide for better joint concentricity. Figure 3 shows the sequence of welding operation to produce robust joints in MA956 tubing. The intended mating pieces are suitably clamped in the head chuck (spinning piece) and the tailstock (stationery) piece. The head stock moves to the starting position (separated by $1 / 8$ " from the tail stock piece) and rotates to the desired rpm. Upon achieving the prescribed flywheel rpm (fixed kinetic energy), the drive mechanism disengages and a fixed weld force is applied which brings the parts in contact. Frictional heat causes mating surfaces to heat up, significantly soften and plastically deform to form a full circumferential through wall-thickness joint. Steep thermal gradients are formed over compact length scales of the order of the heat affected zone width. Flywheel rotation is stopped as rpm drops to a prescribed level and the weld cools while still held firmly in the collets. The entire weld process takes up to 60 seconds. Process variables such as friction force, rotational speed and upset displacement are monitored for evaluation of overall joint performance. A two stage 
variant of this process can independently vary the upset pressure to influence the forging characteristics of the joint region and upset length of the overall joint.
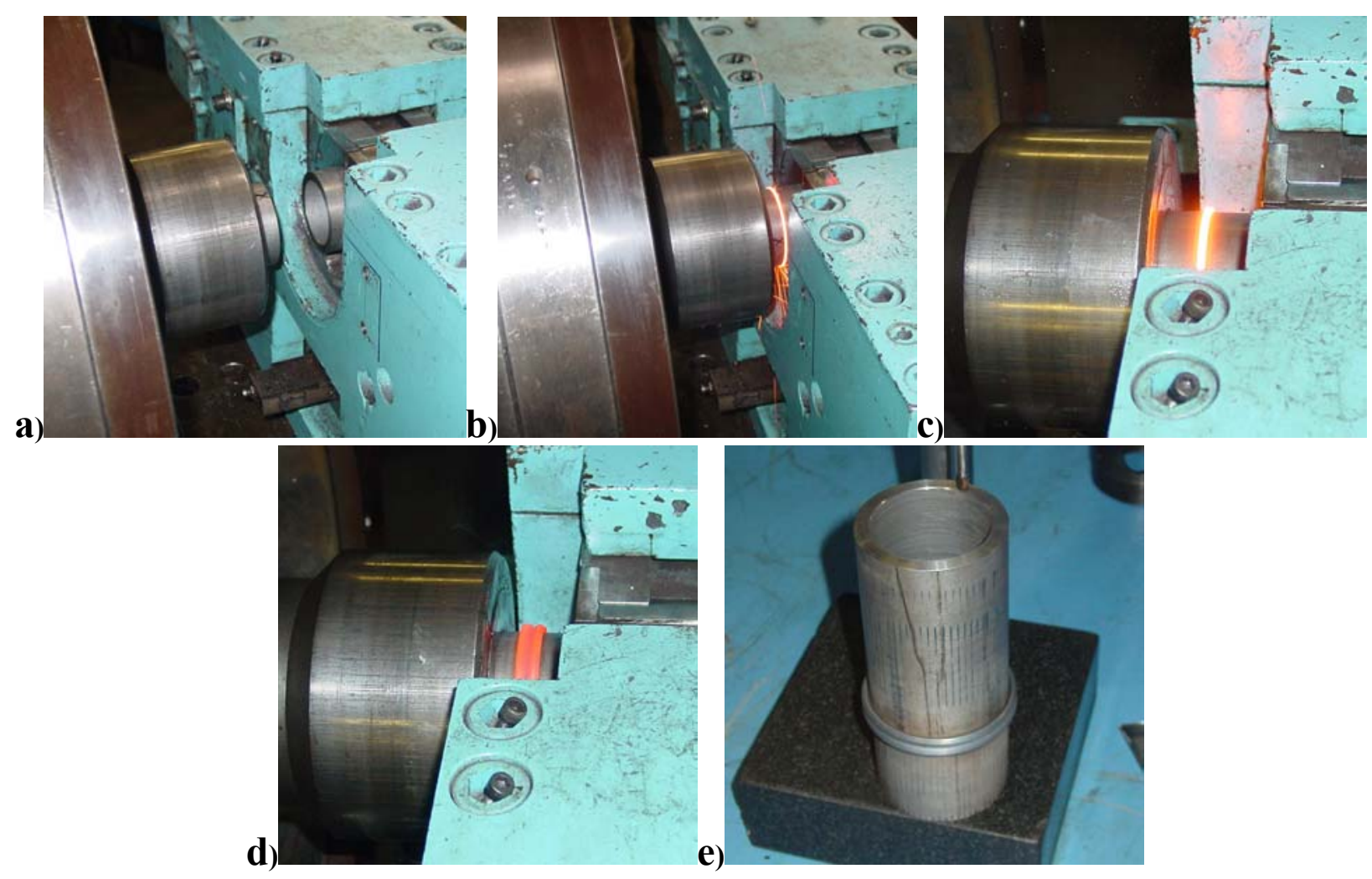

Figure 3. Sequences in the inertia welding of MA956 tube a) spin up of tube, b) initial contact under applied pressure, c) flywheel stopped at a prescribed rpm drop, d) cool down and, e) the as-welded tube section.

Figure 4 shows a sampling of MA956-MA956 butt joints and corresponding material flash produced via different inertia welding conditions. Table 1 list the initial test matrix of MA956-MA956 butt joints produced via inertia welding under Task 1.1 activity. All test conditions produced a robust joint over a $0.125 "-0.662 "$ material upset as evidenced by visual examination. However, Test\#5 created an out-of joint presumably because the machine fixturing became unstable at the high weld loads employed. Furthermore, Test\#6 produced a large material upset exceeding 0.5". This large upset was deemed undesirable for deep hole butt-joints that may require subsequent machining or rebore to remove the excessive internal flash. Such gun-drilling procedures typically introduce additional fabrication

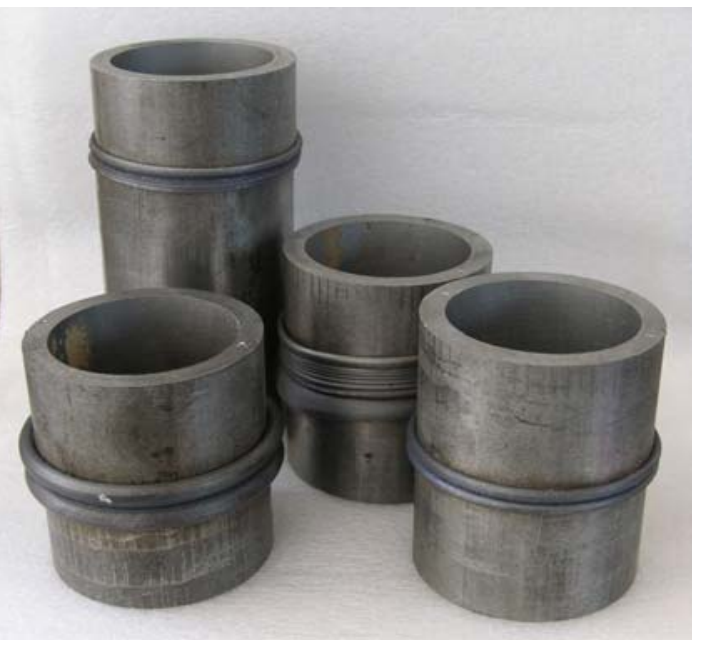

Figure 4. Typical MA956-MA956 butt welds produced under different welding conditions. complications and are best if avoided. With this in mind we concentrated our microstructural evaluation and testing efforts on Test Samples \#1-4 (Table 1) and reported here. 
Table 1: Test matrix of MA956-MA956 tube butt joints produced via inertia welding

\begin{tabular}{|c|c|c|c|c|c|c|}
\hline Test & $\begin{array}{c}\text { Flywheel } \\
\text { WK }^{2}\end{array}$ & Weld Speed & Upset Speed & Weld Force & Weld Upset & Joint Status \\
\hline 1 & 111.5 & 1500 & 500 & 50,000 lbs & 0.153" & OK \\
\hline 2 & 71.5 & 3000 & 500 & 50,000 lbs & 0.498" & OK \\
\hline 3 & 146.5 & 1000 & 500 & $100,000 \mathrm{lbs}$ & $0.125^{\prime \prime}$ & OK \\
\hline 4 & 146.5 & 1500 & 500 & $100,000 \mathrm{lbs}$ & $0.360 "$ & OK \\
\hline 5 & 146.5 & 1700 & 500 & $150,000 \mathrm{lbs}$ & $0.490 "$ & Off-Round \\
\hline 6 & 71.5 & 3000 & 500 & $100,000 \mathrm{lbs}$ & $0.662 "$ & Large upset \\
\hline
\end{tabular}

Looking ahead to Task 3 reporting we note that joints with material upsets in the range of 0.125 " -0.360 " produce the best long term creep response. As such this processing window was then preserved and replicated in subsequent parametric development of Task 1.2 and Task 1.3 activity. The welding parameters were adjusted for size for the transition from Task 1.1 activity on tubes versus the task 1.2 and 1.3 activity on rod samples to yield comparable upsets. Figure 5 shows the IN740-IN740 butt joints from age hardened rod stock and with upsets in the ranges of $0.125 "-0.300$ " for Task 1.2 activity. Similarly, Figure 6 shows the IN740-MA956 dissimilar material joints from rod stock for the Task 1.3 activity with upset in the range of 0.125 " -0.400 ". Asymmetric material flow is noted in dissimilar joints with more flash from the MA956 side.

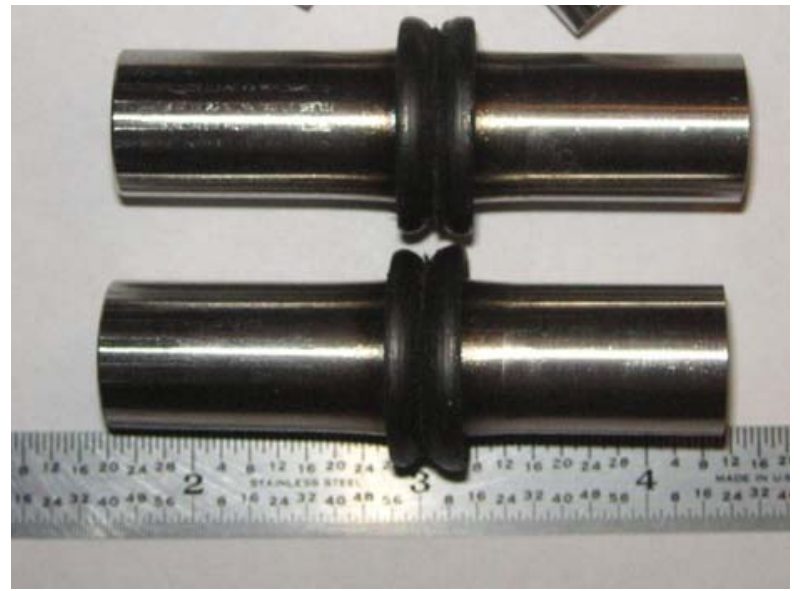

Figure 5. IN740-IN740 rod joints produced with material upsets in the 0.125 " -0.360 " range.

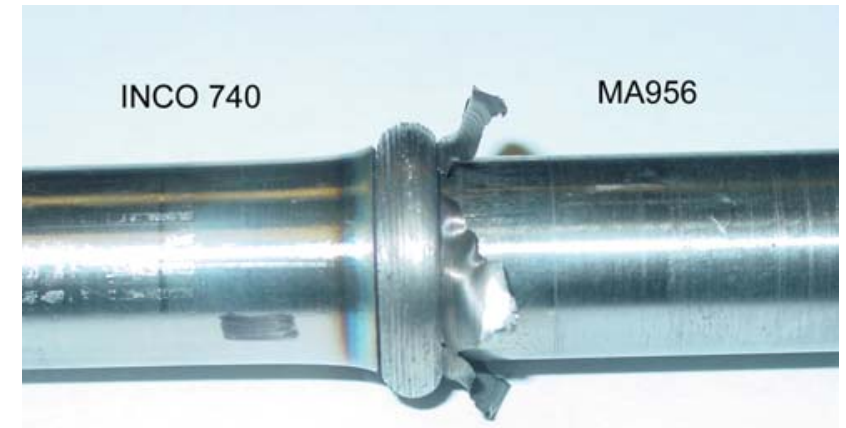

740 TO MA956 UPSET .167

Figure 6. IN740-MA956 rod joints produced with material upsets in the $0.125 "-0.410 "$ range.

Task 2 Results: MA956 material joints from Task 1.1 were processed using the unrecrystallized MA946 tubes provided by the vendor. This unrecrystallized state lends well to processing via dynamic deformation and upset forging typically imposed in inertia welding. However, creep performance is best realized in well annealed ODS microstructures undergoing primary and more importantly secondary grain growth. Thus MA956 material joints from Task 1.1 were recrystallized in Task 2.1 at $1375^{\circ} \mathrm{C}$ for 1 hour (i.e., vendor specified thermal treatment for optimum microstructure) in air. Optical microscopy in Task 2.2 suggests that the welding matrix of Table 1 produces various degrees of primary recrystallization and/or secondary growth in joints 1-4 as outlined in Table 2. Figure 7 shows as-welded and recrystallized views of selected joints of Table 1, with Joint\#3 exhibiting primary and secondary recrystallization. Large aspect 
ratio grains are oberved in the weld zone orthogonal to the tube axis. This aspect of recrystallized grain morphology may dominate hoop creep performance and is discussed in a later section.

Table 2: Recrystallization of MA956-MA956 tube butt joints produced via inertia welding

\begin{tabular}{|c|c|c|}
\hline $\begin{array}{c}\text { Tes } \\
\text { t }\end{array}$ & Recrystallization HT & Joint Region \\
\hline 1 & Tube Segment, $1375^{\circ} \mathrm{C}-1 \mathrm{hr}$ in Air & Primary Recrystallization, fine grains \\
\hline 2 & Tube Segment, $1375^{\circ} \mathrm{C}-1 \mathrm{hr}$ in Air & -NA- \\
\hline 3 & Tube Segment, $1375^{\circ} \mathrm{C}-1 \mathrm{hr}$ in Air & Secondary Recrystallized, coarse grains \\
\hline 4 & Tube Segment, $1375^{\circ} \mathrm{C}-1 \mathrm{hr}$ in Air & Secondary Recrystallized, coarse grains \\
\hline 5 & Tube Segment, $1375^{\circ} \mathrm{C}-1 \mathrm{hr}$ in Air & -NA- \\
\hline 6 & Tube Segment, $1375^{\circ} \mathrm{C}-1 \mathrm{hr}$ in Air & -NA- \\
\hline
\end{tabular}
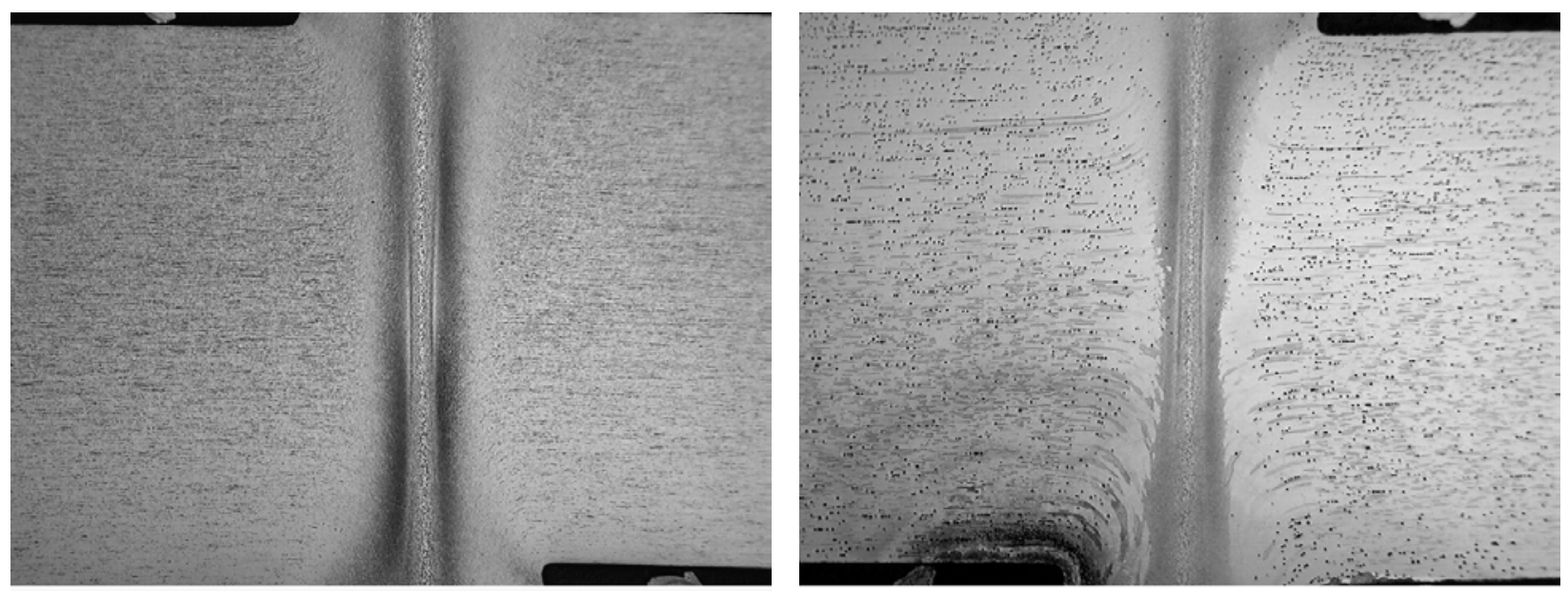

$128 \times 300 \mu \mathrm{m}$

$\# 1$

IFW 1 MA 956 HT 1375

12ax $300 \mu \mathrm{m}$

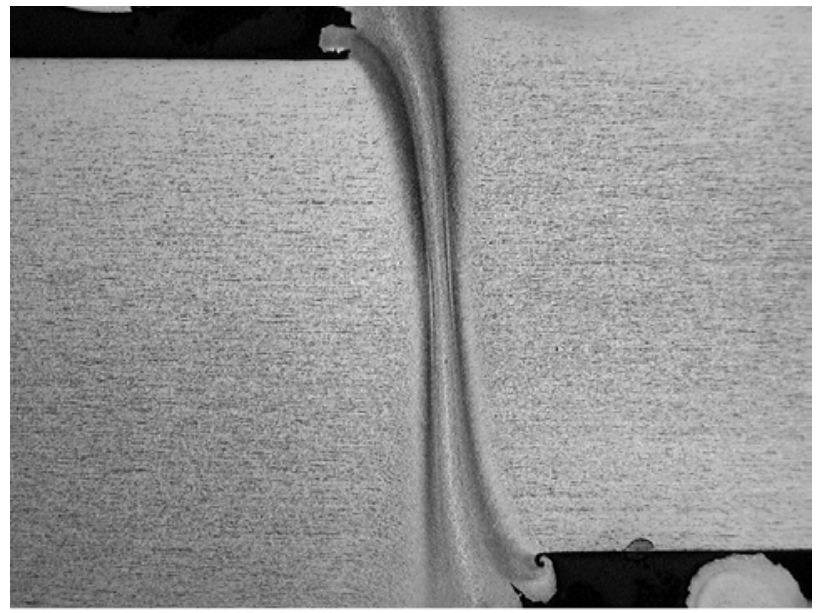

\#4

IFW 3 MA 956 As Weld

$128 \times 300 \mu \mathrm{m}$

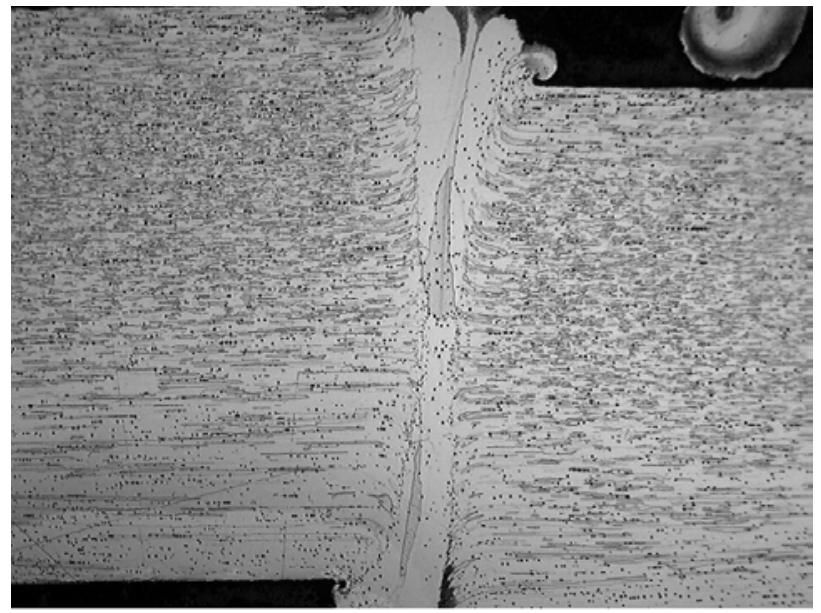

\#3

IFW 3 MA 956 HT 1375

$128 \times 300 \mu \mathrm{m}$

Figure 7. Optical Micrographs of MA956 butt-joints in the as-welded (left) and recrystallized (right) condition. Figure 7.2 and 7.1 (Top) are respectively the as-welded and post-weld heat treated microstructure across the Joint\# 1 where only primary recrystallization is observed. In contrast, Figure 7.4 and 7.3 (Bottom) are the aswelded and post-weld heat treated microstructure of Joint 3 where ample secondary grain growth is observed in the weld region. This latter microstructure yields enhanced hoop creep performance. 
For the dissimilar joints of Task 1.3 preliminary joining of nickel base solid solution strengthened IN601-MA956 was undertaken as a prelude to the nickel base precipitation strengthened IN740-MA956 dissimilar joints. This was primarily designed to explore the subtleties of joining and validating existing MA956 joining methodologies without undertaking the simultaneous complexities from the precipitation hardened microstructure. The desired starting microstructure for IN740 is either the solution treated or precipitation heat treated for maximum strength. Furthermore, the optimum heat-treatment temperature to accomplish a solution or precipitation treatment in IN740 as well as the complete secondary recystallization in MA956 was evaluated. The precipitation strengthened IN740 alloy is expected to be severely affected by a post-weld heat-treatment required for the MA956 tube. This was evaluated to ascertain the eventual starting microstructures for MA956 and IN740 as well as incorporating any changes to the post-weld heat treatment.

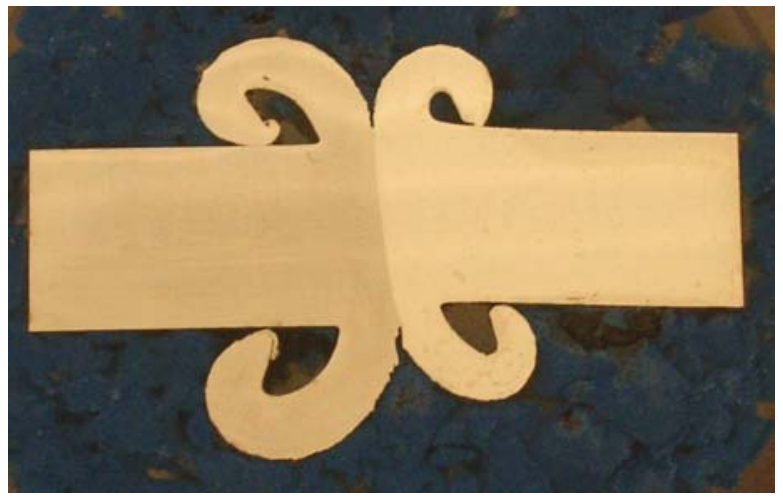

Figure 8. MA956-IN601 dissimilar alloy butt joint.

Fortunately, the solid solution strengthened IN601 (or CCA617) was not subject to such complication and was consequently selected for detailed evaluation. The IN601-MA956 joints shown in Figure 8 were fabricated using the parameter set listed in Table 1 with weld force in the $100,000 \mathrm{lbs}$ and higher range. We note the likely flow stress disparity between the MA956 and
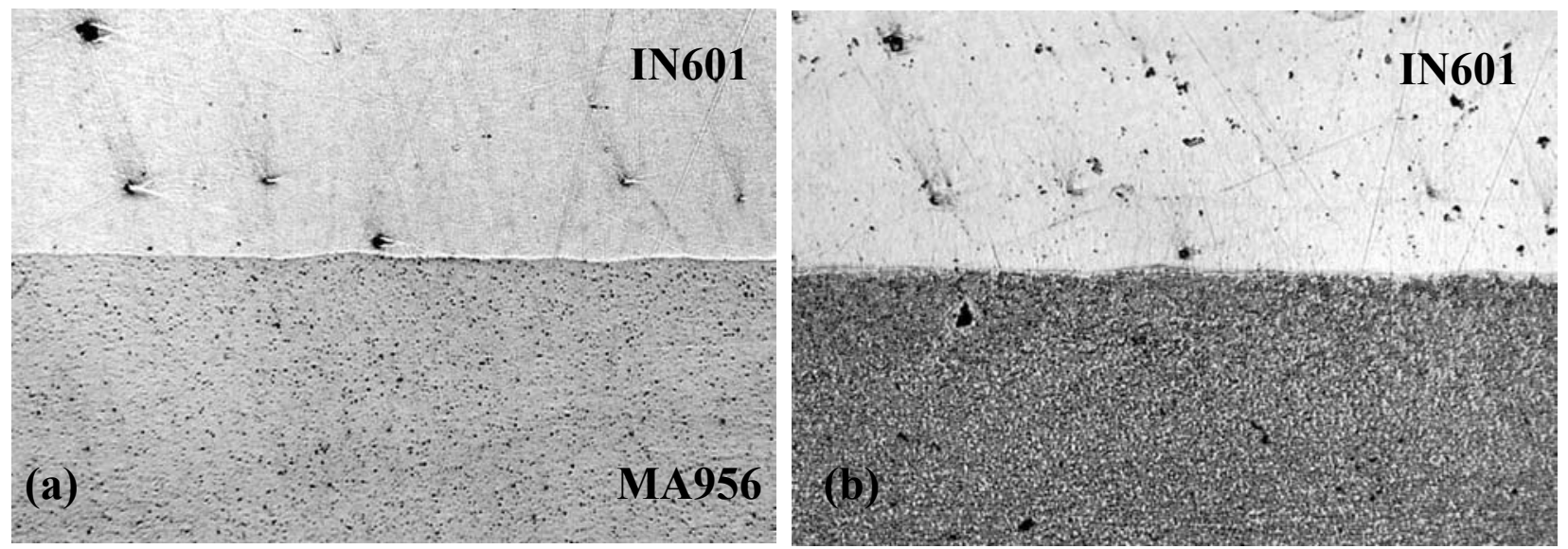

Figure 9: Metallography of dissimilar alloy IN601 and MA956 inertia welded joint in the as polished (a) and etched (b) condition. The interface is clean with a slight intermixed layer seen in the as-polished cross-section.

IN601 at the weld temperature as the material flow at the interface is asymmetrical, with a smaller material flash observed for the IN601 side of the joint, Figure 8. The as-joined dissimilar IN601-MA956 joint was sectioned for microstructural evaluation in Task 2.2 and shown in Figure 9. The as-welded microstructure shows a relatively clean joint with a slight intermixing layer of about $15 \mu \mathrm{m}$ observed at weld interface. A matrix of recrystallization heat-treatments of such joints were attempted in the $1100-1300^{\circ} \mathrm{C}$ range and reported here. The recrystallization treatment for MA956 and IN601 presents some unusual challenges for the current joint as well as for the proposed MA956-IN740 joints. Recall that MA956 is typically joined in the unrecrystallized condition and a post-weld heat treatment is essential. Inconel 601 or 617 are solution strengthened alloys so a repeat thermal excursion is not anticipated to affect the base 
properties of these alloys provided the joint weld thermal excursion is brief and cools rapidly. However, IN740 is a precipitation strengthened alloy which is expected to be severely affected by a post-weld heat-treatment required for the MA956 tube.

An important fabrication perspective was to explore materials with solution annealing temperatures approaching, the nominal MA956 recrystallization temperature. Since MA956 is joined in the unrecrystallized state, a post-weld recrystallization treatment is essential. A candidate alloy with matching solution temperature provides for a robust joint with optimum base material performance while circumventing a repeat thermal excursion step. Table 3 lists the nominal solution temperature, currently in practice, for nickel-base alloy candidates. Such solutionizing treatment can likely be pushed higher based on the melting temperature of the alloy. For example, IN617 solution annealing is performed at $1193^{\circ} \mathrm{C}$ but melts at $1332^{\circ} \mathrm{C}$ (depending on alloy chemistry). As stated earlier, alloy IN740 requires a solution treatment at $1150^{\circ} \mathrm{C}-1200^{\circ} \mathrm{C}$ followed by a precipitation hardening at $760^{\circ} \mathrm{C}-800^{\circ} \mathrm{C}$. A vendor specified heat treatment of $1375^{\circ} \mathrm{C}-1 \mathrm{hr}$ for the MA956 based dissimilar joint is not an option for IN740 that melts in the $1293^{\circ} \mathrm{C}-1369^{\circ} \mathrm{C}$ range.

Table 3: Candidate Material Properties for MA956-Nickel Base Alloy Dissimilar Joints.

\begin{tabular}{|c|c|c|c|c|}
\hline $\begin{array}{l}\text { Candidate } \\
\text { Materials }\end{array}$ & $\begin{array}{l}\text { Solution Anneal, } \\
\text { Recrystallization } \\
\text { Temperature, }{ }^{\circ} \mathrm{C}\end{array}$ & $\begin{array}{c}\text { Alloy } \\
\text { Melting } \\
\text { Temperature, }{ }^{\circ} \mathrm{C}\end{array}$ & $\begin{array}{c}\text { Current } \\
\text { Proposed HT } \\
\text { Temperature, }{ }^{\circ} \mathrm{C}\end{array}$ & $\begin{array}{c}\text { Required } \\
\text { Post Anneal } \\
\text { Treatment }\end{array}$ \\
\hline MA956 & 1375 & 1480 & 1375 & NA \\
\hline IN601 & 1000-1080 & 1360-1411 & 1100 & Fast Cool \\
\hline IN617 & 1193 & 1332-1377 & 1200 & Fast Cool \\
\hline Haynes230 & $1177-1246$ & 1290-1375 & 1250 & Fast Cool \\
\hline IN740 & 1150-1200 & 1293-1369 & 1200 & Aged@750-800 \\
\hline
\end{tabular}

In the case of the IN601-MA956 joint, initial attempts to recrystallize at $1100^{\circ} \mathrm{C}, 1200^{\circ} \mathrm{C}$ and $1250^{\circ} \mathrm{C}$ met with limited success. As described in Table 3, all samples were fast cooled to preserve the solution strengthened characteristics of IN601 alloy. Optical metallography in Task 2.2 indicates no base metal or joint recrystallization was observed at $1100^{\circ} \mathrm{C}$. At $1200^{\circ} \mathrm{C}$, onset of recrystallization was observed in the base metal but not verified in the joint region. At $1250^{\circ} \mathrm{C}$, we have semblance of recrystallization in both base metal and joint region. A further heat treatment at $1300^{\circ} \mathrm{C}$, well below the melting point of IN601, was also attempted. These results are briefly summarized in Figure 10. Figure 10a shows microhardness profiles across the weld interface in the as-welded and heat treated conditions. The ambient temperature hardness profile of MA956 is higher than IN601 for all conditions. Alloy MA956 exhibits only minor hardness drops for heat treatments at $1250^{\circ}$ and $1300^{\circ} \mathrm{C}$ suggesting that recrystallization in the vicinity of the joint is not complete. On the other hand, IN601 exhibits substantial softening at $1250^{\circ} \mathrm{C}$ which is also corroborated at $1300^{\circ} \mathrm{C}$ heat treatment. Figure $10 \mathrm{~b}$ shows a backscatter SEM image of the joint interface, heat treated at $1300^{\circ} \mathrm{C}$, also shows a microhardness indent on the IN601 side. Backscatter image exhibits Z-contrast consistent with the atomic number of the IN601 (brighter) and MA956 (darker) constituents. An interdiffusion boundary layer of about $15 \mu \mathrm{m}$ is also observed. This diffusion region has contrast similar to that of MA956 (as in dark contrast). Note that the hardness indent is clearly on the IN601 side though the edges of the indent stretch across the diffusion boundary layer and stop at the edge of the MA956 region. It is 
surmised that this hardness measurement is impacted by MA956 at the edges of the indent. Deformation in IN601 is evident from the slip lines on the right side of the indent. No slip lines are observed on the left side. Nonetheless, the indent is fairly symmetric and deemed a good measure. Evidence of indent discontinuity is not perceptible at the boundary layer. EDS based chemical profiling of the interface after aggressive heat treatments are reported in Figure 10. Looking ahead to the next section for dissimilar joint testing, the aggressive heat treated samples do exhibit a marginal improvement in observed creep performance via lower observed creep rate.

The requirement for post weld heat treatment (PWHT) in dissimilar joints (to recrystallize MA956) also induces diffusional migration effects given the vast compositional differences for the mating alloys. Figure 11 shows EDS chemical mapping of the e IN601-MA956 joint in the aswelded (left) and the heat treated condition (right). For clarity only the four important atomic species
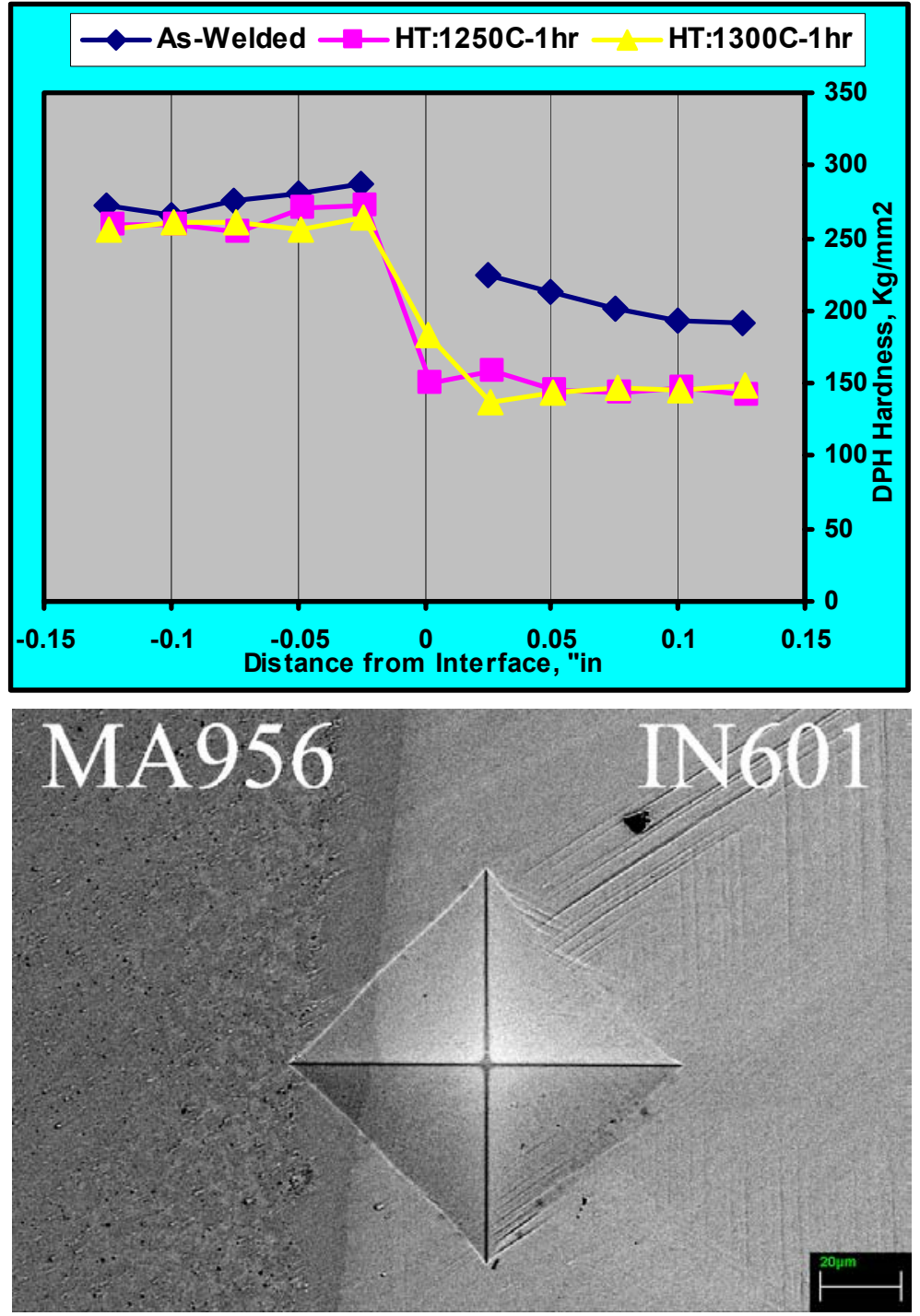

Figure 10.a) Micorhardness profile across the IN601-MA956 dissimilar joint at different HT. b) Backscatter SEM image of the interface (HT: 1300C-1hr) with an hardness indent in the vicinity. $(\mathrm{Al}, \mathrm{Cr}, \mathrm{Fe}, \mathrm{Ni})$ are presented here. The chemical profiles are uniform up to the as-welded joint interface. This is expected for the extremely short duration thermal excursion in the inertia welding process. However, significant diffusional effects are observed for a recrystallization treatment of $1300^{\circ} \mathrm{C}-1 \mathrm{hr}$. Thermally enhanced migration of Ni and Fe to MA956 and IN601 respectively, is expected. The Cr content is essentially similar in either alloy and hence no significant migration was expected. The aluminum depletion from the MA956 and its subsequent migration to IN601 results in a compositional spike at the interface, and its spatial width is consistent with the roughly $20 \mathrm{~mm}$ boundary layer observed at the interface, see Figure 11(b). Such migration, particularly of Al, may impact high temperature corrosion behavior and the joint mechanical strength. In an effort to induce recrystallization of the mating MA956 we are likely to pursue the most aggressive thermal treatment possible without degrading the subsequent joint performance. This example suggests that inherent diffusional effects in heat-treatment or subsequent service require close monitoring. Looking ahead to section 3.2, we note that heat-treatment has marginal beneficial effect on improving creep performance. 


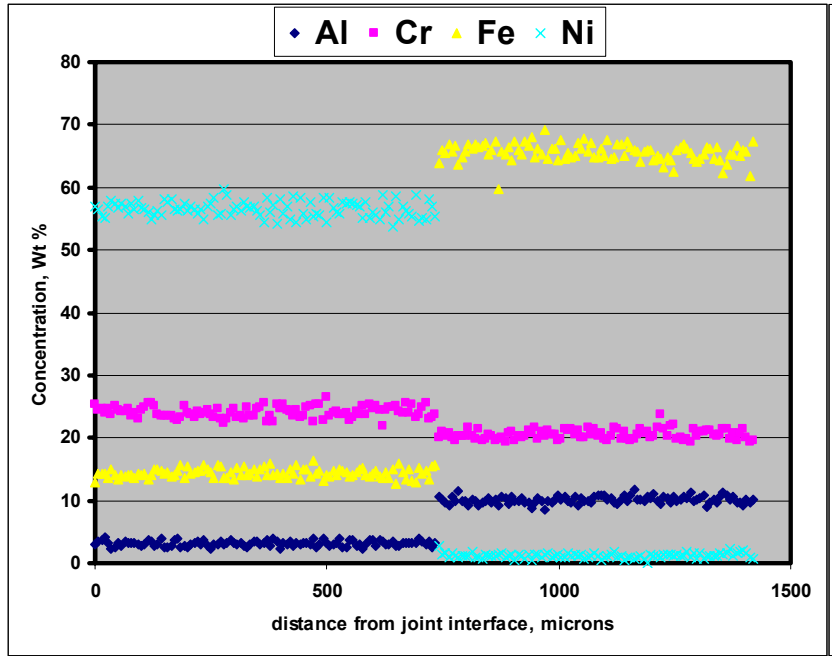

a) As-Welded joint interface

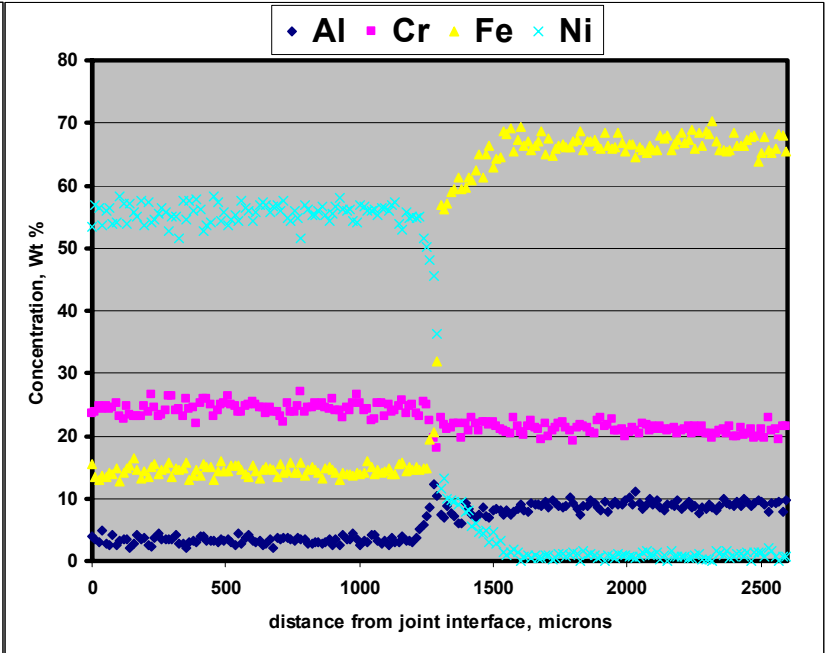

b) Heat treated, $1300^{\circ} \mathrm{C}, 1 \mathrm{hr}$

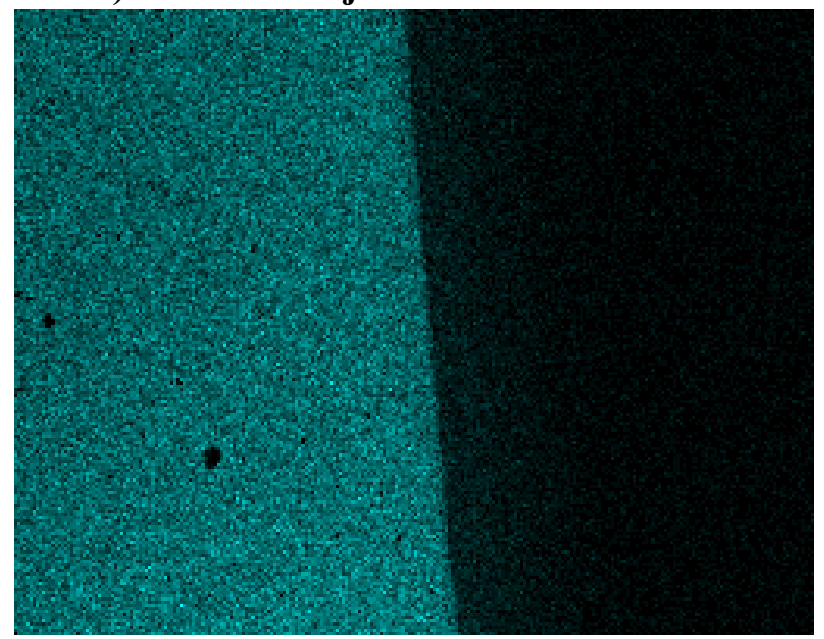

c) Nickel map, Joint heat treated

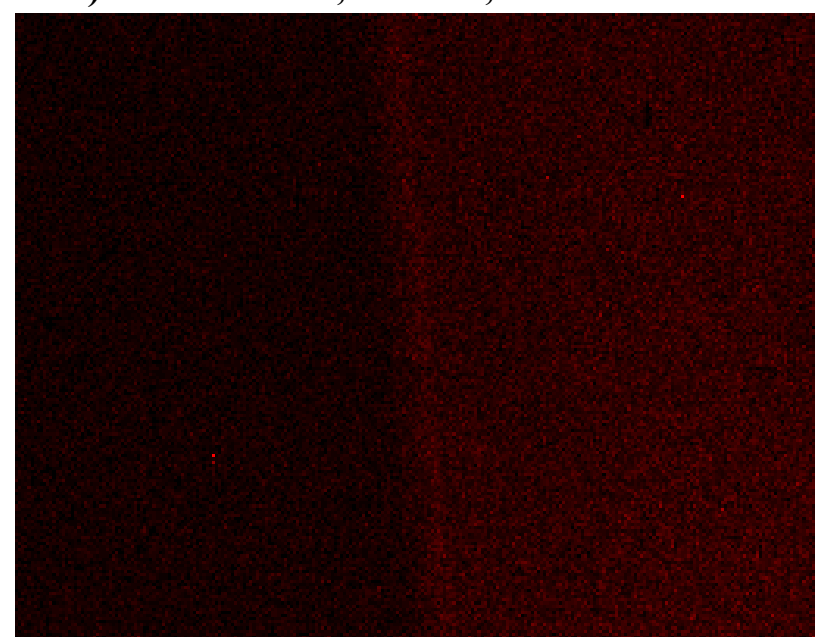

d) Aluminum map, Joint heat treated

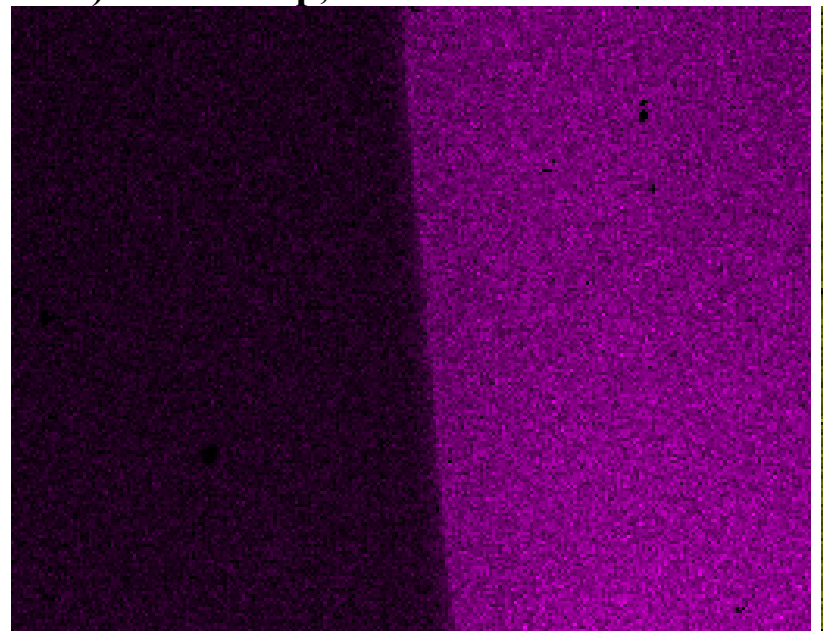

e) Iron map, Joint heat treated

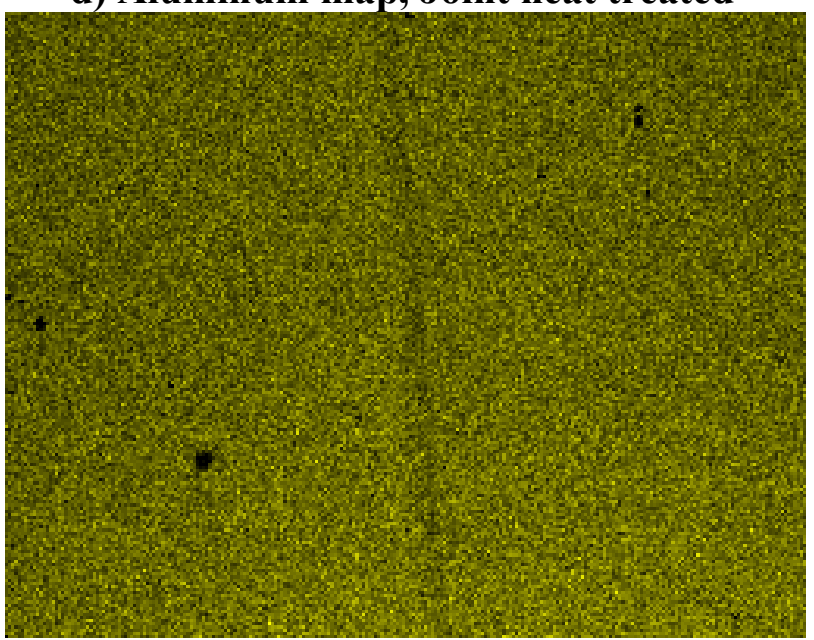

f) Chromium map, Joint heat treated

Figure 11. Compositional profile of $\mathrm{Al}, \mathrm{Cr}, \mathrm{Fe}, \mathrm{Ni}$ species across the IN601 (left)-MA956 (right) inertia welded interface. a) As-welded section, b) heat-treated at $1300^{\circ} \mathrm{C}-1 \mathrm{hr}$. Energy dispersive compositional scans for c) Nickel d) Aluminum, e) Iron and f) Chromium across the heat treated joint interface. 
Ambient temperature bend tests were used in Task 2.3 as a preliminary indicator of robust joints produced in Task 1.1-1.3. The premise of such tests is to ensure that the inertial welded joints have adequate ductility and strength. While this may not be an indicator of high temperature creep strength, it does allow for simple measure of ranking ductile versus brittle joints. In each case we shows joints that were suitably bent to angle of 90 o or better to evaluate joint characteristic. Figure 12a (top) shows the ductile nature of the MA956-MA856 joint segment extracted from the sample tube joint of Figure 3. The flash is machined off prior to bend testing. Large strains on the outer surface fibers produce ductile tearing in what is deemed a robust joint. Figure $12 \mathrm{~b}$ shows similar three point bend testing of as welded IN740-IN740 rod joints of Task 1.2. The initial rod diameter is 0.625 " and the flash material was removed prior to bend testing. Figure 12c (bottom) shows three point bend test for the dissimilar IN740-MA956 joint. There is asymmetric bending as the bend test indicates significant material flow on the IN740 side only. The approximate joint interface is marked with the bend clearly on the IN740 side. This enhanced room temperature flow on the IN740 side is contrary to the inertia welding stage which produced more flash on the MA956 side. This observation was also confirmed for the MA956IN601 tube joint as shown in Figure 8. A likely explanation for this repeated observation is that MA956 undergoes significant softening at the temperature spiked achieved during inertia joining but at room temperature the MA956 has a higher hardness (strength) than the corresponding nickelbase alloy. This is indeed consistent with the room temperature hardness as measured in the as welded MA956-IN601 joint, Figure 10a.
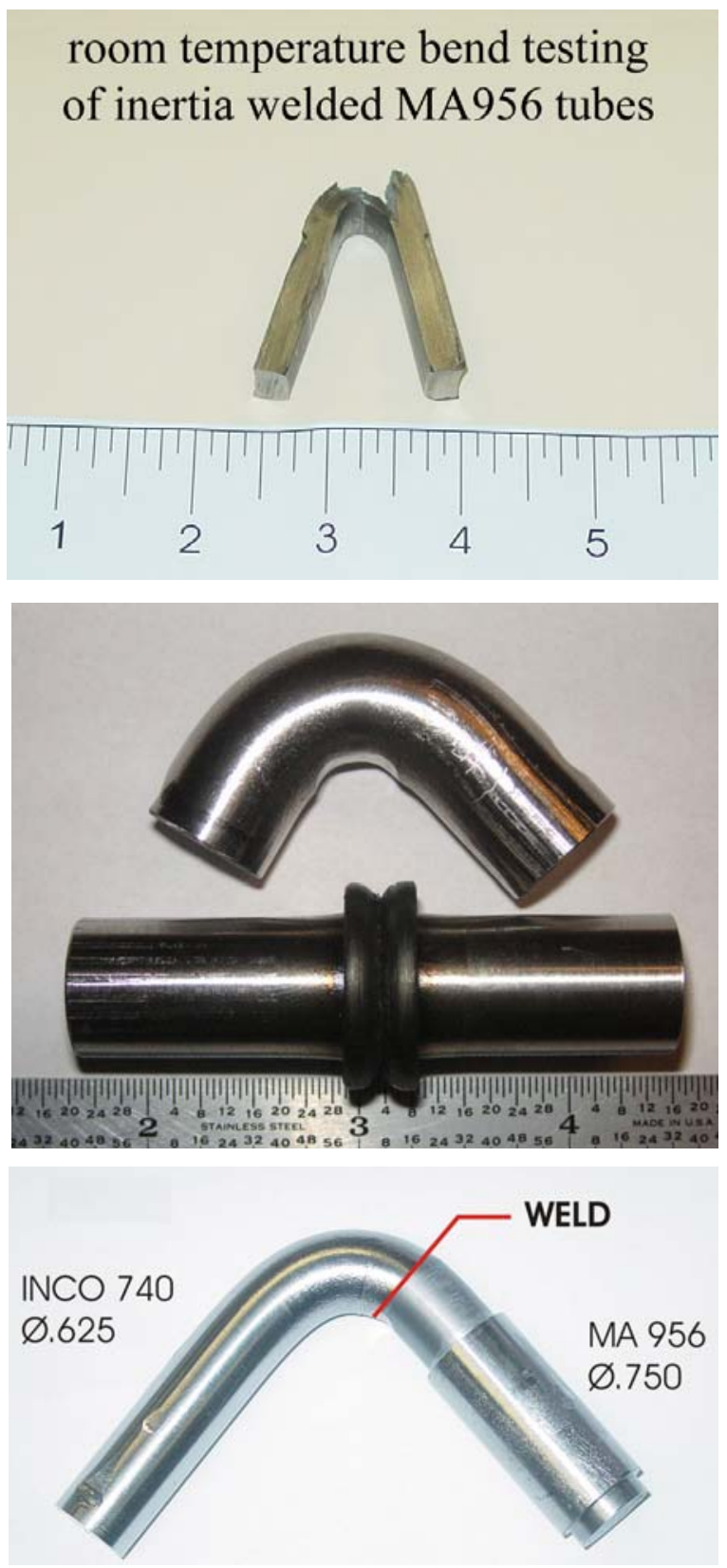

Figure 12. Room temperature three point bend tests in as-welded a) MA956-MA956, b) IN740-IN740 similar and c) IN740 - MA956 dissimilar joints.

Task 3 Results. Following the microstructural examinations conducted in Task 2, the joint geometry and grain structure was deemed suitable for further high temperature creep evaluation. The geometrical considerations for creep testing of joints are an important issue as illustrated here. The baseline hoop creep data for MA956 base material is extracted from 2-1/2"OD tubes that are subsequently flattened with creep samples cut in the transverse orientation. However, for the joint sections, transverse samples are not feasible as the processed joint width of about $300 \mu \mathrm{m}$ (see Figure 6) is considerably narrower than the 0.125 " creep test coupon width and any 
sample cross-section will contain the base material as well. The issue is further exacerbated as the tube joint will need to be flattened to extract the transverse specimen. Thus an alternate strategy of extracting longitudinal specimens, see Figure 13(a), was employed ensuring that the joint section comprises the entire gage cross-section. We note that sample orientation was a particular issue in MA956 tubes on account of the grain shape anisotropy where grains were extended along the longitudinal direction. However, looking back at recrystallized joint microstructure of Figure 7.1 and 7.3 we note that the recrystallized heat affected grain structure appeared to be extended in the radial direction. Thus for the longitudinal samples as spark machined here (see Figure 13(a)) the grain structure in the joint region may very well be so rotated that they are net normal to the eventual loading axis. This would then represent the most severe loading to be experienced on the grain structure under internally pressurized 'service temperature' loading. The obvious outcome of this geometry was that the base material in the gage length was loaded elastically and the bulk of the creep occurs in the small volume of the joint region in the gage length. Accelerated and long term creep data was evaluated only for the tube geometries, i.e., the MA956-MA956 similar joint and the MA956-IN601 dissimilar joint.

\section{$\underline{3.1 \text { Materials Testing of Similar Material Joints }}$}

Samples for the creep testing program were spark machined from joint sections. Figure 13(a) shows the requisite ASTM E-8 micro-creep specimen as cut from the entire tube joint-sections. Thin slices of about $1.0 \mathrm{~mm}$ were further sliced from this bulk sample for high temperature testing. Figure 13(b) shows an initial test for a MA956MA956 but joint tested at a $2 \mathrm{Ksi}$ dead load at $900^{\circ} \mathrm{C}$ temperature. The abrupt failure of the coarse grained MA956 base material, as evaluated previously, was replaced with a nominal creep behavior that exhibits primary, steady state and a brief tertiary creep regime. The mean creep rate over the entire life was measured as $1.0 \mathrm{e}^{-4} /$ day as indicated by the dashed red line on Figure 13(b). A small, but perceptible increase in creep rate was observed as the sample transitioned from steady-state regime to the tertiary regime. The sample failed after a total exposure of 504 hours with a Larsen Miller Parameter $(\mathrm{LMP})=43.87$, with failure occurring in the joint region. Here $L M P=T(20+\log (t)) * 10^{-3}$ with temperature $(\mathrm{T})$ in degrees Rankine and time $(\mathrm{t})$ in hours. Looking ahead to the Task 3 results, we note that creep tests exhibit a high temperature and stress sensitivity as well as a stress threshold. Extended lifetimes are realized when material joints are tested below such safe temperature and stress thresholds. Furthermore, despite large increases in the creep life, via successful manipulation of processing
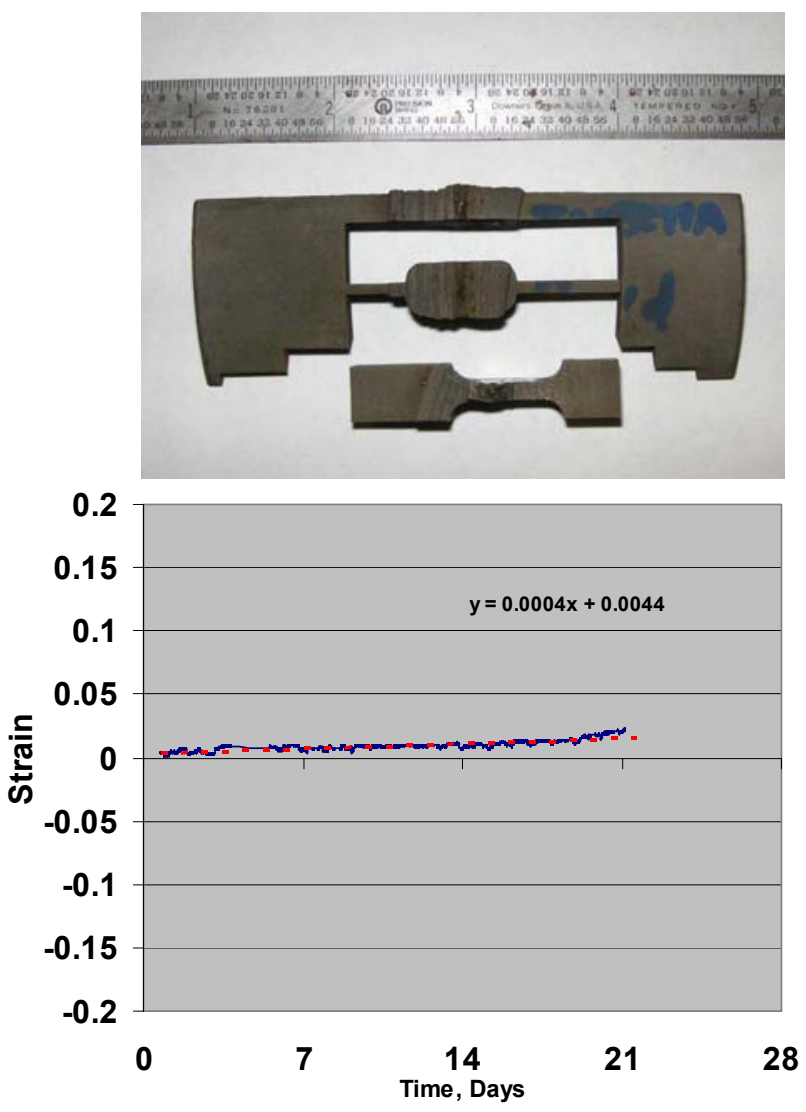

Figure 13a) Creep samples spark machined from the inertia butt welded joints, b) Creep behavior of MA956 butt joint tested at $900^{\circ} \mathrm{C}$ at $2 \mathrm{Ksi}$ stress. 
parameters, failure still occurred at very low strains $(<1 \%)$. Additional tests for similar and dissimilar MA956 butt joints at fixed temperature and stress as well as incrementally increasing stress and/or temperature are reported below.

A comprehensive effort was initiated to evaluate the creep response of joints fabricated in Table 1 . Incremental test regime of Task 3.1 was implemented via periodic temperature increments at constant $2 \mathrm{Ksi}$ stress. These were performed initially to further prescribe the most viable temperature regime for the long term creep tests of Task 3.2. Figure 14 shows the incremental temperature test for Joint 1 (Table 1). We note that the joint exhibits a low and acceptable creep rate at $800^{\circ} \mathrm{C}$ test temperature tested for over 200 hours. However, the test became unstable when temperature raised to $850^{\circ} \mathrm{C}$, and no steady state regime was observed for Joint 1 at this temperature. Failure was observed in the joint region. This experimentally observed poor creep response was not surprising, and in fact consistent, given the fine recrystallized grain structure of this joint 1 as reported in Table 2 and Figure 7.1. The extended tertiary creep regime observed at the $850^{\circ} \mathrm{C}$ test temperature was also consistent with the fine grain recrystallized structure in the joint 1 .

Figure 15 shows a similar incremental temperature test for Joint 3 (Table 1). This test was commenced at $800^{\circ} \mathrm{C}$ test temperature at $2 \mathrm{Ksi}$ stress, and temperature raised in $50^{\circ} \mathrm{C}$ increments about every 200 hours. The test specimen exhibited nearly identical creep rate of about $1.0 \times 10^{-4} /$ day at $800^{\circ} \mathrm{C}, 850^{\circ} \mathrm{C}$ and $900^{\circ} \mathrm{C}$ test temperatures and eventually rose to $8.0 \times 10^{-4} /$ day at $950^{\circ} \mathrm{C}$ with failure observed after a dwell time of 41 hours at this temperature. The improved creep response of joint 3 (Table 1) was consistent with the re-crystallized coarse grained structure of this joint, see Figure 7.3. Such coarse structures do indeed fail with little incremental strain and do not provide an extended tertiary regime as observed for the fine structured joint 1 test in Figure 14.

Creep failure microstructures for the joint 1 and 3 are presented in Figure 16(a) and (b) respectively at low magnification and $16(\mathrm{c})$ and $16(\mathrm{~d})$ respectively at high

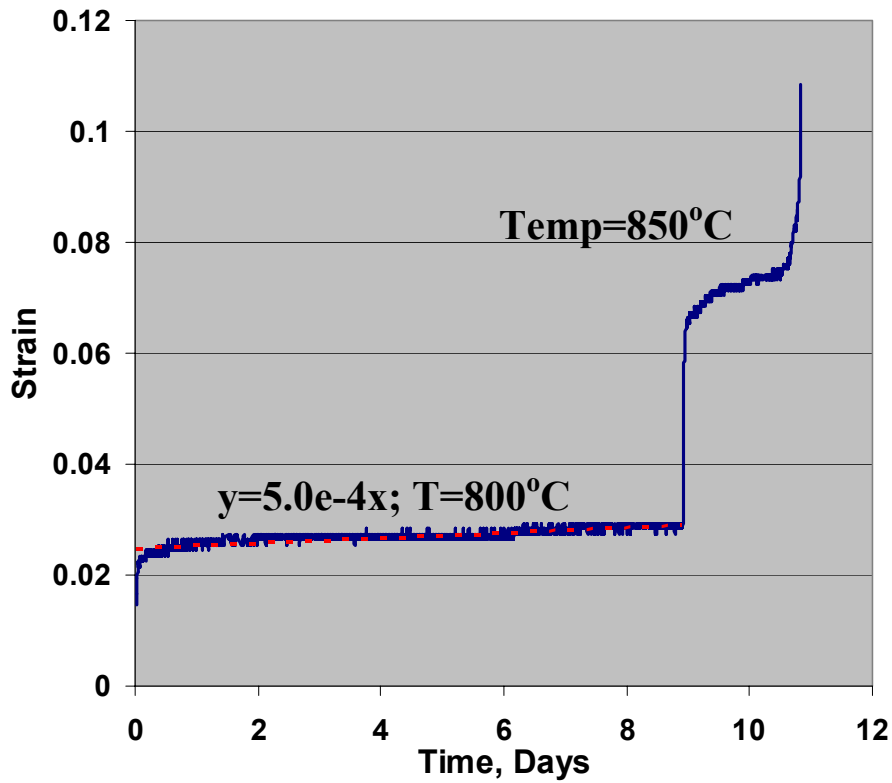

Figure 14. Incremental temperature creep test of similar alloy Joint 1 (Table 1). The fine grain recrystallized structure of the joint region results in poor creep response.

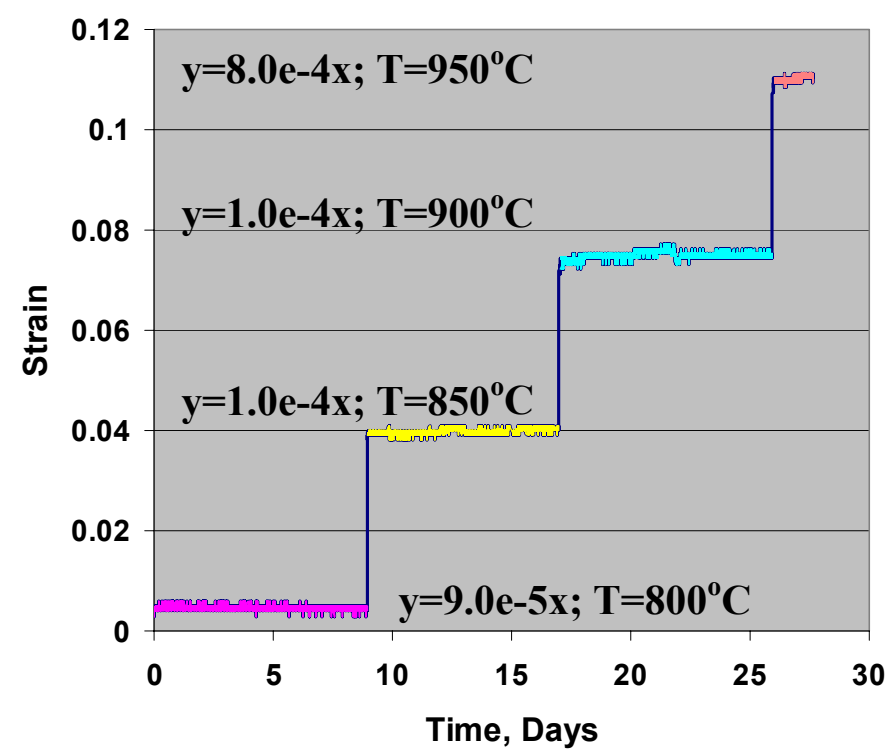

Figure 15. Incremental temperature creep test of similar alloy joint 3 (Table 1). The coarse grained recrystallized structure of the joint region results in good creep response. 
magnification. Failure in Joint 1, Figure 16(a),(c) exhibited features of inter-granular type separation despite the large observed strain to failure (Figure 14). Note in Figure 16(a) the necking observed at the sample gage length. We surmise that failure occurred by extensive grain boundary sliding that provides a concomitant reduction of the sample cross-section. Failure in Joint 3, Figure 16(b),(d) exhibited features of trans-granular type with evidence of localized plasticity in the form of periodic extended ligaments. This localized plasticity does not lend itself to any macroscopically measurable strain. It is surmised that this failure occurred via the nominal creep cavitation and subsequent linking of cavities to failure. Such fracture observations provided insight into developing an appropriate set of material joining parameters that may provide the most optimum creep performance.

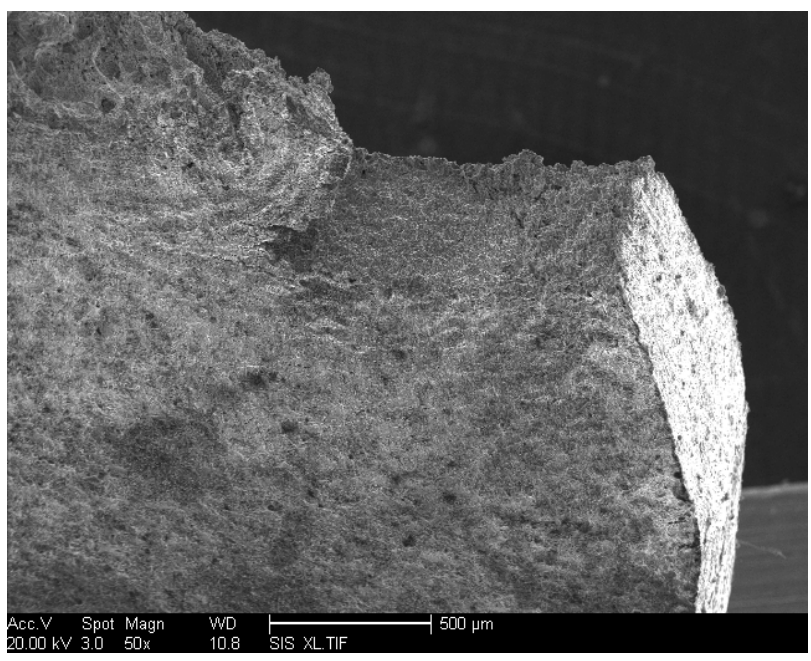

a)

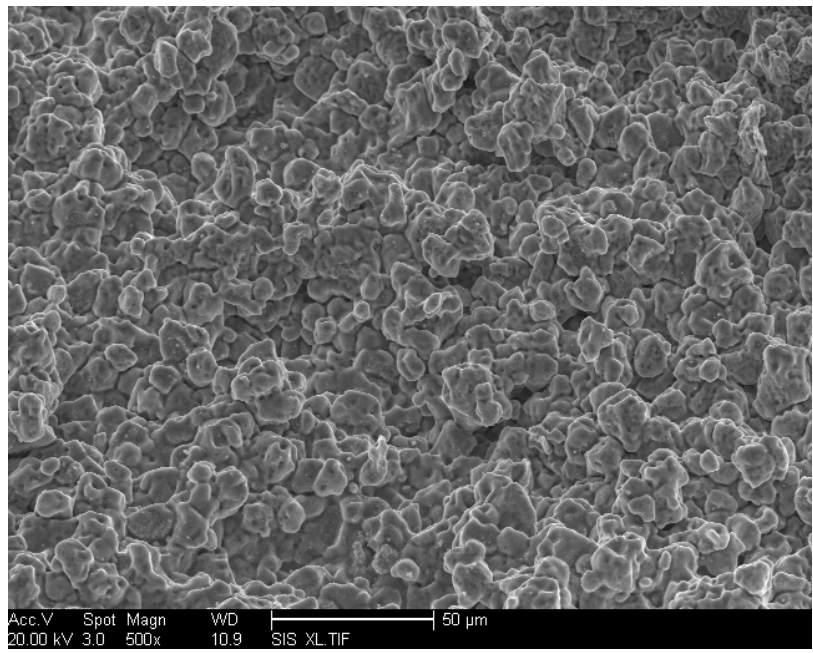

c)

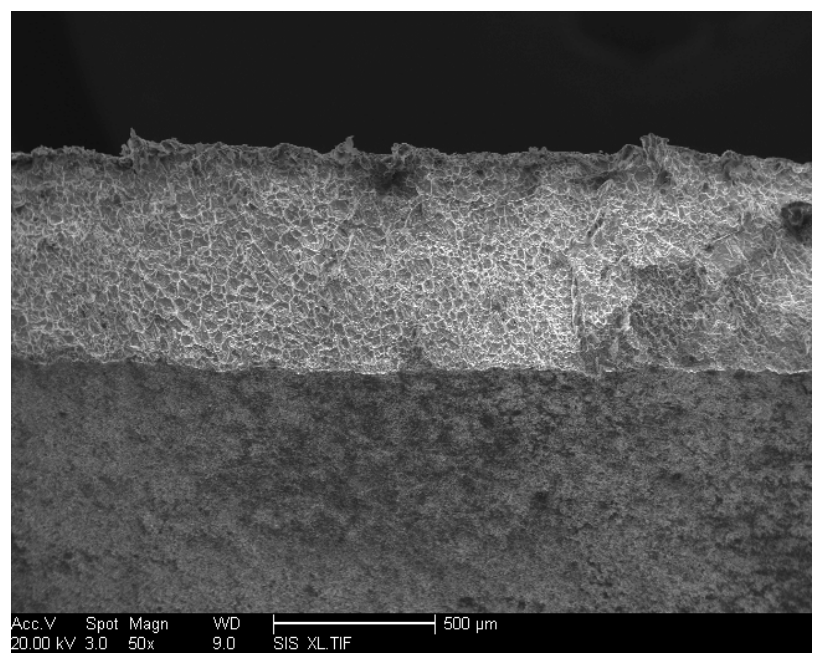

b)

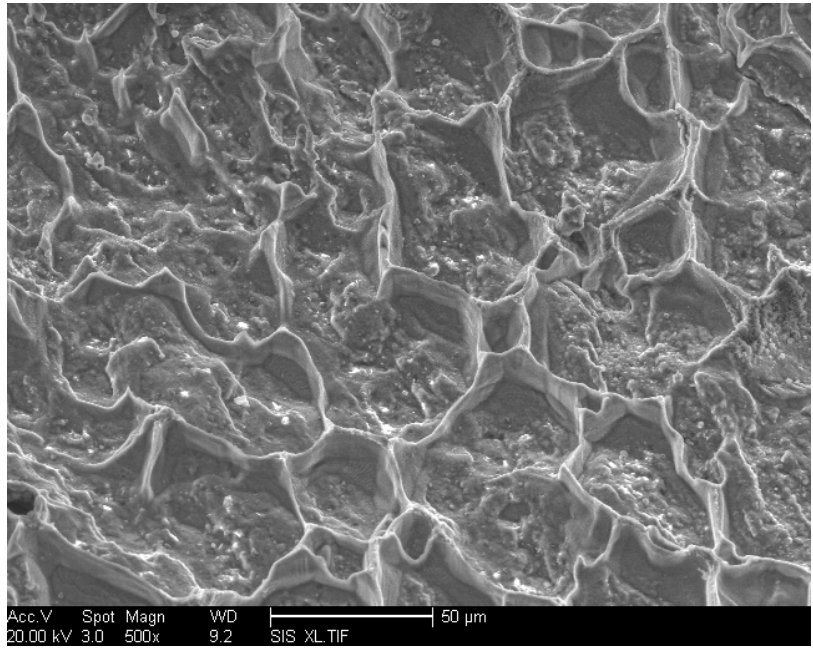

d)

Figure 16. Scanning electron micrographs of creep test failures in Joint 1 failed at $850^{\circ} \mathrm{C}$ (left (a),(c)) and Joint 3 failed at $950^{\circ} \mathrm{C}$ temperature (right, (b),(d)). Both tests performed at $2 \mathrm{Ksi}$ and the improved performance of Joint 3 versus Joint 1 is attributed directly to the coarse grained recrystallized microstructure (see Figure 6.3). Such micrographs provide ready assessment of the efficacy of joining parameters employed and the subsequent recrvstallization microstructure that mav improve ioint creep performance as evaluated here.

It was noted that transgranular fracture evidence of joint\# 3 (Figure 16b, 16d) did not evolve with test temperature. Failures at higher or lower temperatures, Figure 17a, produced similar 
fractography evidence. In the secondary recrystallized joint $\# 3$, the occurrence and distribution of fine grained regions in the failed sample cross-section, Figure $17 \mathrm{~b}$, may affect creep life. The statistical significance of such effects requires a large data set and remains to be explored.

a)
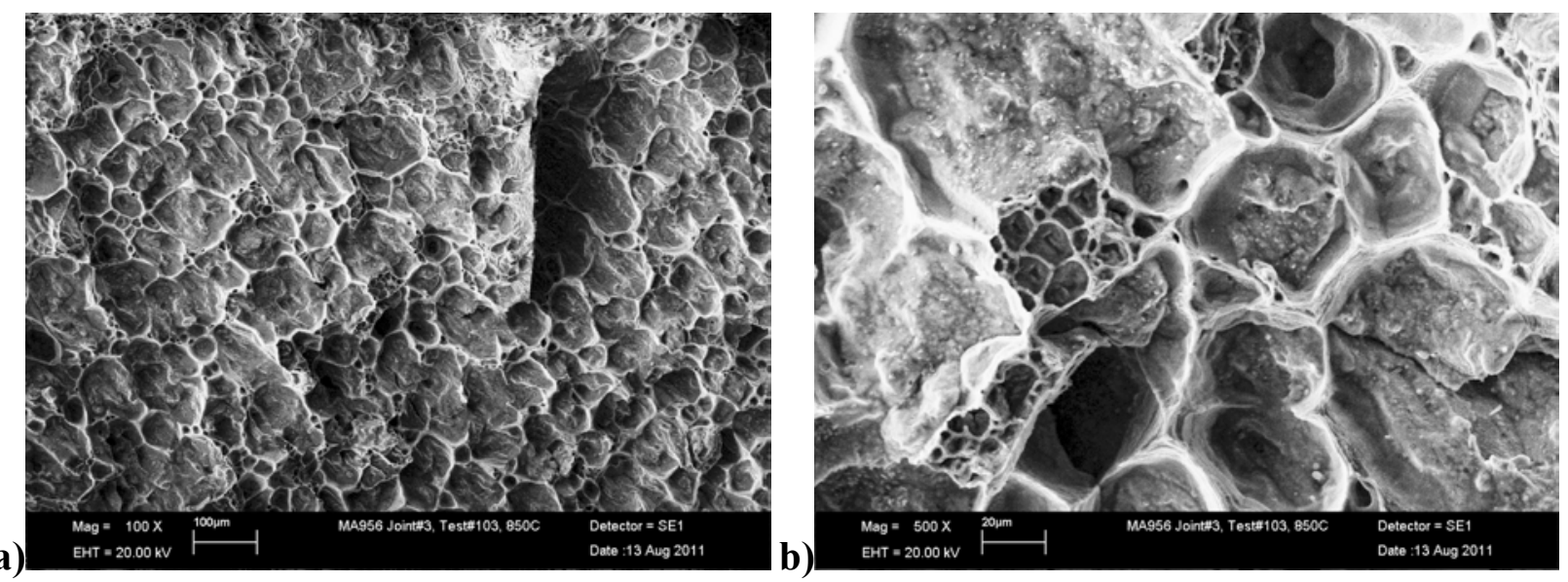

Figure 17. a) Scanning electron micrographs of creep failure in Joint 3 tested at $900^{\circ} \mathrm{C}$. b) Close up detail (right) indicating the random distributions of small grained regions (with small diameter lobes) in the test cross-section.

Table 4: Creep Test Performance for MA956-MA956 Similar Joints

\begin{tabular}{|c|c|c|c|c|c|c|}
\hline & MA956 Joint Processing \& HT & $\operatorname{Temp}^{\circ} \mathrm{C}$ & Stress Ksi & $\begin{array}{c}\text { Life, } \\
\text { Hrs }\end{array}$ & LMP & $\begin{array}{c}\text { Strain } \\
\text { rate/day }\end{array}$ \\
\hline 1 & MA956, As-received, $1375^{\circ} \mathrm{C}, 1 \mathrm{hr}$, Air & 900 & 2.00 & & 46.09 & \\
\hline 2 & Inertia Weld, HT $1375^{\circ} \mathrm{C}, 12 \mathrm{hr}$, Air & 850 & 2.00 & 2196 & 47.20 & $1.0 \times 10^{-4}$ \\
\hline 3 & Inertia Weld, HT $1375^{\circ} \mathrm{C}, 12 \mathrm{hr}$, Air & 900 & 2.00 & 390 & 47.71 & $2.0 \times 10^{-4}$ \\
\hline 4 & Inertia Weld, HT $1375^{\circ} \mathrm{C}, 12 \mathrm{hr}$, Air & 950 & 2.00 & 102.6 & 48.47 & $4.0 \times 10^{-4}$ \\
\hline 5 & Inertia Weld, HT $1375^{\circ} \mathrm{C}, 12 \mathrm{hr}$, Air & 975 & 2.00 & 19 & 47.81 & $9.0 \times 10^{-4}$ \\
\hline 6 & Inertia Weld, HT $1375^{\circ} \mathrm{C}, 12 \mathrm{hr}$, Air & 975 & 2.00 & 25 & 48.08 & $4.6 \times 10^{-4}$ \\
\hline 7 & Inertia Weld, HT $1375^{\circ} \mathrm{C}, 12 \mathrm{hr}$, Air & 925 & 2.00 & 478 & 48.92 & $2.4 \times 10^{-4}$ \\
\hline 8 & Inertia Weld, HT $1375^{\circ} \mathrm{C}, 12 \mathrm{hr}$, Air & 900 & 2.00 & 1021 & 48.59 & $1.4 \times 10^{-4}$ \\
\hline 9 & Inertia Weld(3), HT $1375^{\circ} \mathrm{C}, 1 \mathrm{hr}$, Air & 900 & 2.00 & 256 & 47.33 & $1.0 \times 10^{-4}$ \\
\hline 10 & Inertia Weld(3), HT $1375^{\circ} \mathrm{C}, 1 \mathrm{hr}$, Air & 950 & 2.00 & 41 & 47.59 & $8.0 \times 10^{-4}$ \\
\hline 11 & Inertia Weld(4), HT $1375^{\circ} \mathrm{C}, 1 \mathrm{hr}$, Air & 900 & 2.00 & 76 & 46.21 & \\
\hline 12 & Inertia Weld(4), HT $1375^{\circ} \mathrm{C}, 1 \mathrm{hr}$, Air & 900 & 2.00 & 185 & 47.03 & $7.0 \times 10^{-5}$ \\
\hline 14 & Inertia Weld (3)HT $1375^{\circ} \mathrm{C}, 12 \mathrm{hr}$, Air & 900 & 2.00 & 312 & & $1.0 \times 10^{-4}$ \\
\hline 15 & Inertia Weld(3), HT $1375^{\circ} \mathrm{C}, 1 \mathrm{hr}$, Air & 850 & 2.00 & 2048* & 47.14 & $6.0 \times 10^{-5}$ \\
\hline 16 & Inertia Weld(4), HT $1375^{\circ} \mathrm{C}, 1 \mathrm{hr}$, Air & 850 & 2.00 & 7473 & 48.27 & $4.0 \times 10^{-5}$ \\
\hline 17 & Inertia Weld(3), HT $1375^{\circ} \mathrm{C}, 1 \mathrm{hr}$, Air & 850 & 2.00 & 9725 & 48.50 & $4.0 \times 10^{-5}$ \\
\hline 18 & Inertia Weld(4), HT $1375^{\circ} \mathrm{C}, 1 \mathrm{hr}$, Air & 900 & 2.00 & 1277 & 48.80 & $9.0 \times 10^{-5}$ \\
\hline
\end{tabular}

*Test 15 failed shortly after temperature raised to $900^{\circ} \mathrm{C}$

Table 4 lists the creep test results for the MA956-MA956 similar joints. Test 1 was the base hoop creep performance for the MA956 recrystallized tube. Results indicated that the measured creep rate/day increased from a benign $1.0 \times 10^{-4}$ at $850^{\circ} \mathrm{C}$ test temperature to an aggressive 5.0$9.0 \times 10^{-4}$ at the $975^{\circ} \mathrm{C}$ test temperature. Long term MA956-MA556 joint tests indicated a firm $2 \mathrm{ksi}$ creep stress threshold performance at $850^{\circ} \mathrm{C}$ with a maximum exposure of 9725 hours recorded during this test program. MA956 joint test data indicate that prolonged heat treatments 
at temperature improve creep response, perhaps by reducing the incidence of un-recrystallized stringers in the test cross-section, Figure 17b. Long term creep tests (Test\# 16,17) at fixed temperature and stress establish the full characteristics of the creep curve - with steady state creep rate stabilizing at values lower than recorded in the initial primary creep stage of testing.

\subsection{Materials Testing of Dissimilar Material Joints:}

High temperature creep testing of MA956-IN601 dissimilar material joint is reported. The dissimilar joint was fabricated using un-recrystallized MA956 that required to be recrystallized via a post weld heat treatment. The optimum temperature for MA956 heat-treatment is $1375^{\circ} \mathrm{C}$ but such an aggressive heat-treatment for a dissimilar joint has been the subject of earlier discussion, see Table 3. We noted in Table 3, that while the optimum solution anneal temperature for IN601 is $1000-1080^{\circ} \mathrm{C}$ it has a melting temperature of $1360-1411^{\circ} \mathrm{C}$. This leads to the premise that perhaps aggressive heat-treatments could be attempted without melting the IN601 component. Re-crystallization treatments were attempted for 1-hour at

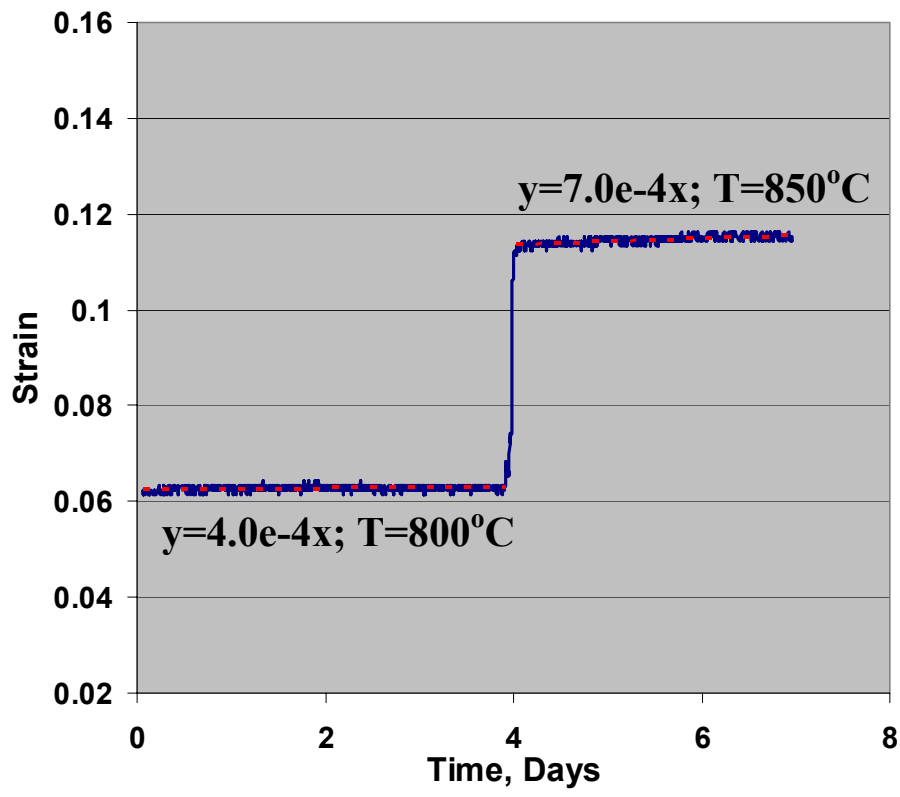

Figure 18. Incremental temperature creep test of dissimilar alloy joint recrystallized at $11300^{\circ} \mathrm{C}$. The joint performance is inferior to the MA956-MA956 joint, figure 10. $1250^{\circ} \mathrm{C}$ and $1300^{\circ} \mathrm{C}$ in air and air cooled as suggested protocol, Table 3. The hardness profiles and details of the interface structure were presented earlier in Figure 10.

Incremental creep temperature jump test data for the joint re-crystallized at $1300^{\circ} \mathrm{C}$ is shown in Figure 18. The test was initiated at $800^{\circ} \mathrm{C}$ at a constant load stress of $2 \mathrm{Ksi}$. This $2 \mathrm{Ksi}$ stress was consistent with the loading of all other tests in this program. The observed creep rate was $4.0 \times 10^{-4} /$ day at $800^{\circ} \mathrm{C}$, tested over a $100 \mathrm{hr}$ period and rose to $7.0 \times 10^{-4} /$ day at $850^{\circ} \mathrm{C}$. The joint failed at this $850^{\circ} \mathrm{C}$ test temperature at 78 hours. We note that the creep response of the dissimilar joint is considerably inferior to that observed for fully re-crystallized coarse grain MA956 joint of Figure 17. Though both samples exhibit failure at apparent creep rates in the 7.0e-4 range, this creep rate was observed at the lower $850^{\circ} \mathrm{C}$ temperature in the MA956/IN601 joint. In examining the $800^{\circ} \mathrm{C}$

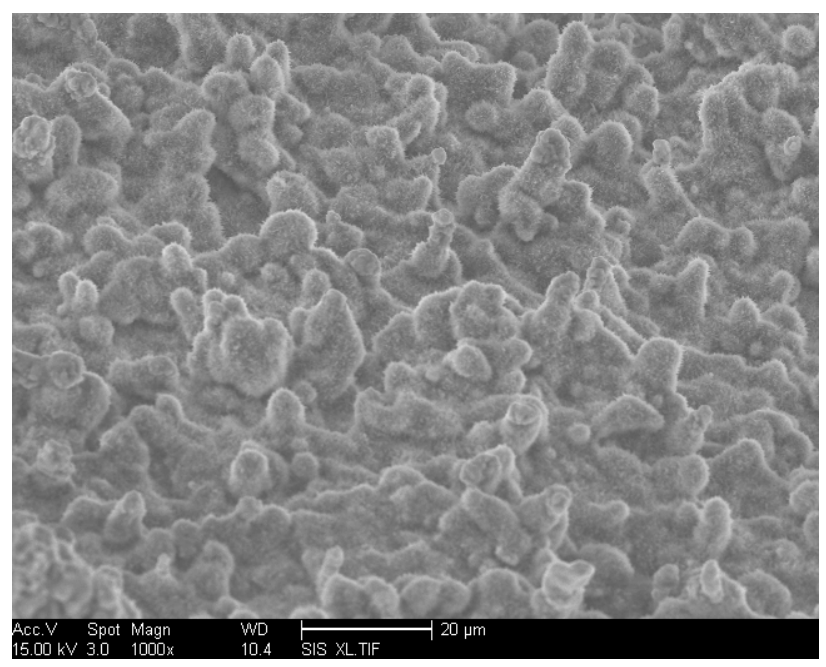

Figure 19. Scanning electron micrograph of creep test failure substructure in dissimilar joint failed at $850^{\circ} \mathrm{C}$. 
creep rate we note that similar creep rates $\left(5.0 \times 10^{-4} /\right.$ day $)$ were also observed in the insufficiently re-crystallized microstructure of the MA956-MA956 joint\# 1, Table 1 as shown in Figure 16(a),(c). This observation was consistent with the microhardness measurement of Figure 9(a) where little hardness change is observed for MA956 even after the $1300^{\circ} \mathrm{C}$ heat treatment.

Figure 19 shows the creep fracture evidence for the dissimilar joint test reported in Figure 18. The failure substructure shows nodules of the order or $2-5 \mu \mathrm{m}$ similar to features observed for the insufficiently re-crystallized MA956-MA956 Joint 1, Table 1 as shown in Figure 16(c). Such similarities in failure may be co-incidental as the tertiary creep regime of Figure was not observed in Figure 18. We note that such dissimilar joint tests are inherently capped by the creep performance limits of IN601. However we also note that failures occurred in the vicinity of the joint and such inertia joining microstructure modifications need further exploration.

Table 5: Creep Test Performance for MA956-IN601 Dissimilar Joints.

\begin{tabular}{|c|c|c|c|c|c|c|}
\hline & MA956 Joint Processing \& HT & $\operatorname{Temp}^{\circ} \mathrm{C}$ & Stress Ksi & $\begin{array}{l}\text { Life, } \\
\text { Hrs }\end{array}$ & LMP & $\begin{array}{c}\text { Strain } \\
\text { rate/day }\end{array}$ \\
\hline 1 & MA956, As-received, $1375^{\circ} \mathrm{C}, 1 \mathrm{hr}$,Air & 900 & 2.00 & & 46.09 & \\
\hline 2 & Inertia Weld, HT $1250^{\circ} \mathrm{C}, 1 \mathrm{hr}$, Air & 800 & 2.00 & 136* & - & \\
\hline 3 & Inertia Weld, HT $1250^{\circ} \mathrm{C}, 1 \mathrm{hr}$, Air & 850 & 2.00 & 27 & 43.33 & \\
\hline 4 & Inertia Weld, HT $1250^{\circ} \mathrm{C}, 1 \mathrm{hr}$, Air & 800 & 2.00 & 192 & 43.03 & $1.0 \times 10^{-4}$ \\
\hline 5 & Inertia Weld, HT $1300^{\circ} \mathrm{C}, 1 \mathrm{hr}$, Air & 800 & 2.00 & 787 & 44.24 & $3.0 \times 10^{-4}$ \\
\hline 6 & Inertia Weld, HT $1300^{\circ} \mathrm{C}, 1 \mathrm{hr}$, Air & 800 & 2.00 & $173 *$ & - & \\
\hline 7 & Inertia Weld, HT $1300^{\circ} \mathrm{C}, 1 \mathrm{hr}$, Air & 850 & 2.00 & 78 & 44.27 & $7.0 \times 10^{-4}$ \\
\hline 8 & Inertia Weld, HT $1300^{\circ} \mathrm{C}, 1 \mathrm{hr}$, Air & 800 & 2.00 & 712 & 44.15 & $4.0 \times 10^{-4}$ \\
\hline 9 & Inertia Weld, HT $1300^{\circ} \mathrm{C}, 1 \mathrm{hr}$, Air & 800 & 2.00 & 392 & 43.65 & $1.0 \times 10^{-5}$ \\
\hline 10 & Inertia Weld, As Received & 800 & 2.00 & 253 & 43.28 & $2.0 \times 10^{-4}$ \\
\hline 11 & Inertia Weld, As Received & 800 & 2.00 & 230 & 43.20 & $1.0 \times 10^{-4}$ \\
\hline 12 & Inertia Weld, As Received & 800 & 2.00 & 228 & 43.20 & $1.0 \times 10^{-4}$ \\
\hline
\end{tabular}

*Test Truncated, No failure recorded.

Table 5 lists the creep test data for MA956-IN601 dissimilar joints. The performance of such dissimilar joints was much inferior to the MA956-MA956 joints, being capped by the creep response of the weaker IN601 constituent. Looking back to the diffusional migration, Figure 11, the impact on ensuing creep life was mixed. For example, creep tests of aswelded samples produced life times of 253 and 230 hours, exhibited a tertiary creep regime and failed with appreciable strains, Figure 20. Some minor decay was observed for the limited data recorded for the $1250^{\circ} \mathrm{C}$ heat treatment. However, there is a small, but reproducible, improvement in creep life for joints heat treated at

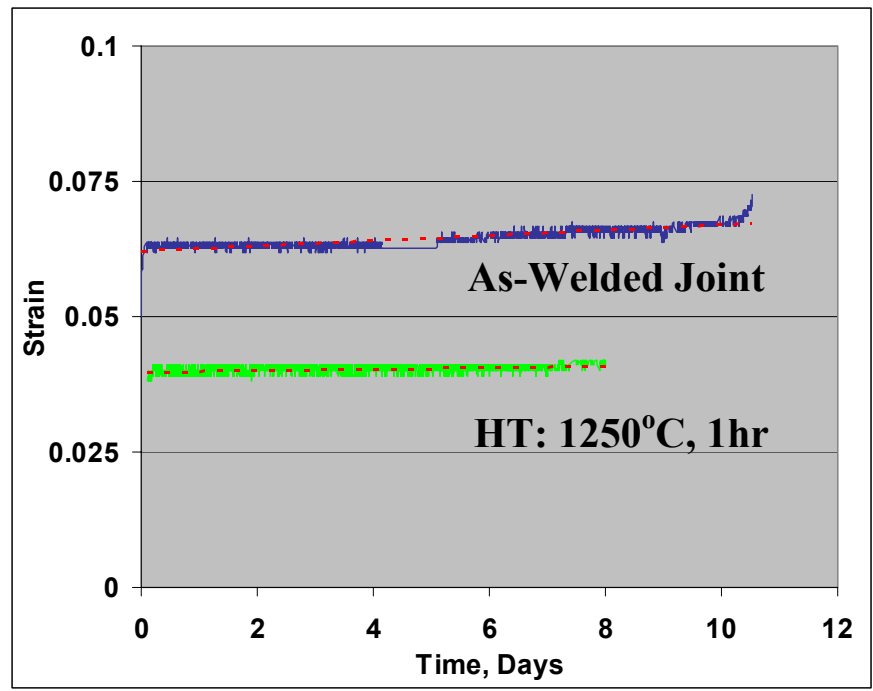

Figure 20: Differences in creep response for the as-welded and heat treated MA956-IN601 joints. As-welded samples show a brief but distinct tertiary regime and fail at high levels of strain. Plots are arbitrarily displaced for clarity 
$1300^{\circ} \mathrm{C}-1 \mathrm{hr}$ (see tests\#4-8, Table 5). Neither heat treatment produced any creep ductility as seen for the as-welded samples, Figure 17. Mechanistic reasons for such disparity are of interest and hitherto unexplored.

\section{§ 4. Summary \& Conclusions}

Task 1 joining trials for similar MA956-MA956, similar IN740-IN740 and dissimilar IN740MA956 welds were completed. In addition, Task 1.3 was supplemented with a solution strengthened CCA601 (IN601) alloy. Initial success with solution strengthened IN601 alloy prompted an expansion of our effort to additional similar candidates initially identified in Figure 1 and further explored in Table 3. Both Haynes 230 and the IN617 alloys present opportunities for dissimilar MA956-Haynes230 and MA956-IN617 tube to tube and tube to cap joint configurations and are of continuing and future interest.

Optical microscopy of MA956-MA956 similar joints suggested that the test matrix produced different levels of primary and secondary recrystallization in the butt-joint and the heat affected zone. Incremental temperature creep testing of such similar alloy joints pointed to direct benefits of various joining parameters (of Table 1) that yielded coarse grained re-crystallized structures and consequently vastly improved creep response as evidenced for tests of Joint 1 and 3. Such coarse grained structures are essential and the underlying fabrication techniques must facilitate such development for improved creep performance. Furthermore, the signature fracture evidence of joints 1 and 3 was deemed useful in selecting optimum performing joints. Both Joint 3 and Joint 4 produced secondary recrystallization in the joint region and the joining parameters as listed in Table 1 are similar except for the weld rpm. A weld rpm of 1500 in Joint 4 produced a much larger upset of 0.360 " compared to the 0.125 " upset for joint 3 processed at $1000 \mathrm{rpm}$.

An alternate view of joint processing parameters vis-à-vis observed creep life is shown in Figure 21 for all tests at $2 \mathrm{Ksi}$ stress [8]. The creep performance profile is shown for the three series of joints produced via different weld upset (Table 1) and recrystallization temperature. At the outset the results confirm the importance of processing parameters in dictating overall creep response as indicated by extended creep life at progressively higher temperatures. The 2Ksi creep stress performance curves indicate approaching a $850^{\circ} \mathrm{C}$ threshold temperature where test life was extended to several thousand hours, Table 4, even though the data presented in Figure 21 is only projected to 2400 hours of test life. We note the combined effect of

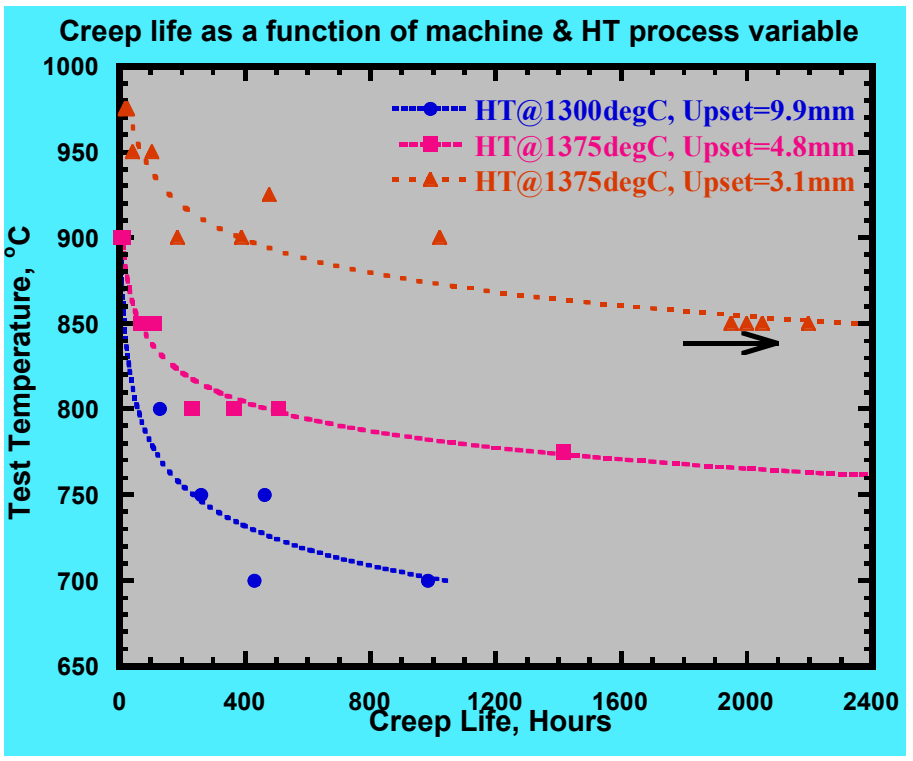

Figure 21. Observed creep life at temperature for three different processed inertia welded joints all tested at $2 \mathrm{Ksi}$ stress. Current results (top curve, brown) are compared to earlier results $\lceil 81$. aggressive recrystallization treatment and the reduced forge upset, which consequently produced a reduced HAZ width, and improved creep life at progressively higher temperatures. Aggressive 
recrystallization temperatures were decidedly beneficial but since $1375^{\circ} \mathrm{C}$ is the vendor proposed recrystallization temperature limit, any further gains were only possible via further manipulating the inertial welding process parameters. In keeping with the general trend of reducing the joint HAZ width, joints were produced via a combination of reducing energy input and forge upset process parameter variables. A peak Larsen Miller Parameter of 48.80 was recorded for similar MA956-MA956 joints as measured for a $900^{\circ} \mathrm{C}$ creep test (test\#18, Table 4). The threshold creep performance has been systematically improved to $850^{\circ} \mathrm{C}$ for joint tests of Table 4 with exposure times of 9725 hours. Thus, the notion of improving joint creep performance via manipulating the factors that dictate HAZ width has significant merit as demonstrated here. The threshold stress and temperature driven failure was evident in Test 15 (Table 4) which had steady performance at $850^{\circ} \mathrm{C}$ but despite the stable $2000 \mathrm{hr}$ exposure at this temperature - the sample failed quickly as the temperature was raised to $900^{\circ} \mathrm{C}$. The practical implications of thermal fluctuations in a real working environment must be considered for such threshold (stress, T) driven ODS alloys.

Optical metallography, SEM and EDS compositional profiling of the MA956-IN601 dissimilar joint section was completed for the as-welded and heat treated sections. Attempts to arrive at a suitable post weld heat-treatment to achieve or maintain the optimum properties in the respective base metals as well as in the joint region met with limited success. The heat treatment in this particular case cannot be $1375^{\circ} \mathrm{C}$ as it risks melting the IN601 alloy. Attempts at recrystallizing the joint grain structure at $1300^{\circ} \mathrm{C}$ appeared promising. However, large compositional migration as noted in Figure 11 suggests that such measures should be closely monitored to preserve the corrosion protection and mechanical integrity of the interface. The aluminum concentration spike at the interface, Figure 11(b), needs to be reconfirmed for other tests - as it reflects both the loss of the corrosion protection reservoir in the MA956 as well as the embrittlement behavior upon its localization - which may also promote intermetallic formation. The performance of the $1300^{\circ} \mathrm{C}$ re-crystallized joints was indeed marginally better than that observed for the $1250^{\circ} \mathrm{C}$ heat-treatment. Nonetheless, the dissimilar joint exhibits poor performance similar to the insufficiently re-crystallized MA956/MA956 butt joints, of Figure 14. It is recognized that dissimilar joints will derive their creep response from the weaker component, i.e., the Ni-base alloy (solution strengthened or precipitate strengthened) and that the creep behavior of dissimilar alloy joints may be inherently constrained by the creep performance of the Ni-Base solid solution strengthened alloy, and consistent with the results observed here. Nonetheless, we also note failures occur in the vicinity of the joint and that joint substructure plays a role. Since Nickel base alloys have inferior creep performance than ODS alloys, the challenge is to develop and optimum post-weld microstructure in the mating Ni-base alloys as well, perhaps in preference to the ODS alloys. Subsequent dissimilar joint tests attempted without any post weld heat treatment as un-recrystallized ODS segment may well be superior to IN601 in the as-welded configuration. Indeed the experimentally recorded creep life of aswelded MA956-IN601 joints is similar and within the bounds of experimental scatter. However, there is one marked difference in that the as-welded joints exhibit a brief but definite tertiary creep regime prior to failure.

Finally, we reiterate that the test geometry of samples extracted from tubes is such that the coarse grained structure of the HAZ was orthogonal to the loading axis. In a real life internally pressurized tube - such pancake shaped grains will be more suitably aligned to the hoop loading environment. Thus, full scale tests of internally tube joints are recommended as the next iteration of subsequent research programs. 


\section{§ 5. References}

1 R. Viswanathan, R. Purgert, U. Rao. "Materials for Ultra-Supercritical Coal-Fired Power Plant Boilers." Materials for Advanced Power Engineering, 2002, Proc. II. Forschungszentrum Julich GmbH, 2002. 1109-1129

2 R. Viswanathan, J. F. Henry, Alstom, J. Tanzosh, G. Stanko, J. Shingledecker and B. Vitalis, "Materials for ultrasupercritical coal fired power plant boilers" Proc. $29^{\text {th }}$ Coal Technology Conf., April 18-22, 2004, Clearwater, FL.

3 J.M. Klara, "HIPPS: beyond state of the Art, Part I", Power Engineering, 12, 37-39 (1993);

ibid "HIPPS: can compete with conventional PC systems: Part II", Power Engineering, 13, 20-23 (1994)

4 F.L. Robson, J. Ruby and D.J. Seery, "Repowering with High-Performance Power Plant Systems (HIPPS)" Proc. Pittsburgh Coal Conf., pp. 162-167, Sept 1996

5 USC Program Task 5 Report to DOE, May 2006, unpublished report, private communication 6 J.K. Tien and T. Caulfield (eds): Superalloys, Supercomposites and Superceramics, Academic Press INC (London) LTD, 1989, p.142-143.

7 C.T. Sims \& W.C. Hagel (eds.): The Superalloys, John Wiley, New York, 1972, p.509-532.

8. B.K. Kad "Solid State Joining of Oxide Dispersion Strengthened Ferritic Alloy Tubes" 8 th Int. Charles Parsons Conference, Portsmouth, UK, 2011 